\title{
EMS-based mutants are useful for enhancing drought tolerance in spring wheat
}

Sadaf Zahra ${ }^{1}$, Sana Zulfiqar ${ }^{2,3}$, Momina Hussain ${ }^{2}{ }^{4}$, Muhammad Akhtar ${ }^{5}$, Tayyaba Shaheen ${ }^{1}$, Mehboob-ur-Rahman ${ }^{2,3 *}$

1 Department of Bioinformatics and Biotechnology, GC University Faisalabad

2 Plant Genomics \& Mol. Breeding Lab, National Institute for Biotechnology \& Genetic 5 Engineering (NIBGE), PO Box 577, Jhang Road, Faisalabad, Pakistan.

3 Department of Biotechnology, Pakistan Institute of Engineering and Applied Sciences 7 (PIEAS), Nilore, Islamabad, Pakistan

4 Department of Biotechnology, Faculty of Life Sciences, University of Okara, Okara

5 Nuclear Institute for Agriculture and Biology (NIAB), Faisalabad, Pakistan

\section{* Corresponding author}

E-mail:mehboob_pbd@yahoo.com ormehboob@nibge.org

\begin{abstract}
Sustainable wheat production in drought prone areas can be achieved by developing resilient wheat varieties. In the present study, chemical mutagenesis was used to induce mutations in a cultivated wheat variety 'NN-Gandum-1'. In total, 44 mutants were selected based on their high yield potential for exposing to well-watered $\left(\mathrm{W}_{1}\right)$ and rainfed $\left(\mathrm{W}_{2}\right)$ conditions for one season. Then 24 mutants were selected, and were exposed to $W_{1}$ and $W_{2}$ regimes. On the basis of least relative reduction in physiological parameters under $\mathrm{W}_{2}$ regime, five mutants were selected for conducting exome capturing assays. In total, 184 SNPs were identified in nine genes (ABC transporter type 1, Aspartic peptidase, Cytochrome P450, transmembrane domain, Heavy metal-associated domain, HMA, NAC domain, NAD (P)-binding domain, S-type anion channel, Ubiquitin-conjugating enzyme E2 and UDP-glucuronosyl/UDP-glucosyltransferase). Maximum number of mutations were observed in chr.2D, which contained mutations in three genes i.e. ABC transporter type 1, NAD (P)-binding domain and UDP-glucuronosyl/UDP-glucosyltransferase which may have a role
\end{abstract}


in conferring drought tolerance. The selected mutants were further tested for studying their biochemical responses under both the regimes for two years. The extent of membrane damage was estimated through malondialdehydeand hydrogen per oxidase and tolerance to drought stress was assessed via antioxidant enzymes in leaves. The selected mutants under drought stress increased the accumulation of proline content, total soluble sugars, total free amino acids, while decreased total chlorophyll content, carotenoids and total soluble protein. Finally, the procedure of narrowing down the number of developed mutants from a large mutation population $(>4000)$ is found useful for exploring the complex trait like drought without compromising yield potential. These mutants can further be explored to understand the genetic circuits of drought tolerance in wheat which will pave the way towards improving livelihood of resource poor farming community mostly relying on cereal food.

Keywords: Triticum aestivum L., EMS, Biochemical and physiological assay, Exome capture, SNPs, Drought

\section{Introduction:}

Wheat (Triticum aestivum L.)is cultivated in more than 60 countries on 219.52 million hectares with an annual production of 758.27 million metric tons (https://apps.fas.usda.gov/psdonline/circulars/production.pdf).Cereals have central role in global food security, predominantly in developed countries. Huge efforts have been made to improve/sustain wheat production by developing advanced varieties with improved genetics. However, there are still many factors which significantly decrease the wheat production [1].

Water deficit is predominant among the abiotic stresses that risks the cultivation of cereal crops [2-3]. Around $60 \%$ of wheat production is primarily affected by the limited supply of water [4-6] Under the current scenario of climatic change, it could be inferred that water stress will aggravate in future [ $\underline{7}-\underline{8}]$. Currently, improving yield potential and breeding drought tolerant wheat varieties are in progress to meet the increasing food demand of growing population of the world [9-12]. With the onset of first green revolution (thirst agriculture revolution) between 1950s and 1960s, substantial advancements towards increasing wheat production were made by introducing dwarfing genes into the old wheat cultivars using conventional breeding techniques [13]. This 
improved germplasm containing the dwarfing genes was widely used for developing new wheat varieties, as a result, the wheat production increased significantly. There are still many areas left undiscovered which together reduce the wheat production globally especially drought stress [1415]. To survive water stress via conventional breeding is challenging as it is difficult to regulate the multigenic response of abiotic stress tolerance [16-17]. To combat dehydration, plants bring several changes in their physiological, morphological, biochemical and molecular mechanisms $[\underline{18}-\underline{21}]$.

Understanding the adaptive response of important phenotypic traits that contribute to improved productivity during stress is essential in order to comprehend physiological as well as genetic methods of wheat adaptation [22-23]. As a response mechanism, some biochemical catalysts are produced, these alter the expression and regulation of multiple osmolytes, consequently leading to adverse homeostasis disruption [24] by affecting plant cellular mechanisms [25-26]. Droughtinduced production of chemically reactive oxygen species (ROS) that expose cells to oxidative damage, results in membrane disability (lipid peroxidation), leakage of ions, breakage or cleavage of DNA strand at various levels, degradation of biomolecules, eventually leading to tissue damage and programmed cell death [27-30]. Though, cereals under abiotic stresses accumulate low molecular weight compatible solutes like sugars and proline to improve tolerance to drought stress [31].While, total chlorophyll and carotenoid contents decline under water restricted conditions $[\underline{32}]$.

Various anti-oxidants (both enzymatic and non-enzymatic) play important role in plants to combat dehydration by controlling oxidative damage [33]. It was observed that concentration of various antioxidant enzymes like peroxidase (POD), superoxide dismutase (SOD) and catalase (CAT) increased significantly to mediate the effects of ROS for mitigating the oxidative stress in wheat [34-37]. Hence, enzymatic antioxidants have important role in coping drought stress, and thus can be used in screening drought tolerant wheat varieties [10].

For improving the genetics of wheat cultivars for coping drought, it is important to create allelic diversity followed by screening the wheat material under rainfed conditions. Mutagenesis had been an effective strategy to develop improved wheat genotypes and cope drought stress [ $\underline{38}-\underline{41}]$. It was widely used to induce genetic variations and also the most effective and economical means for combating stresses [42]. Mutations can be spontaneous or induced artificially by exposing the 
biological material with physical or chemical mutagens [43]. Either for forward or reverse genetics, chemical mutagenesis is a standard choice for analysing gene function [44]. EMS (ethyl methane sulphonate), is extensively applied chemical mutagen which creates abrupt point mutations in plant genome [느-47]. Resultantly, mutated wheat lines and dwarf mutants have been produced, which are characterized to be drought resistant [뇨-49].

With the genetic advancements, NGS (next-generation sequencing) tools can be used to assess genetic variation and polymorphism [50-51]. Like other polyploids, wheat genome can withstand neutral mutations as these accumulated changes in genes which have no significant effect on survival of wheat plant [52-53]. For many plant species, complement of variant can be mapped via WGS (whole genome sequencing) [54] and these causal mutations can be recognized by identifying mapping regions [55]. Wheat has large genome size of around $17.6 \mathrm{~GB}$ and sequencing the whole wheat genome is quite expensive (International Wheat Genome Sequencing Consortium, 2014). In fact, exome-capturing approach can be used to lessen the cost of WGS [ㄷ]. Exome-capturing has been used to detect and sequence genetic variants among coding sequence (CDS) within wheat genome [57] and SNPs discovered by the exome capture assay can be helpful to detect mutations in putative candidate genes, mapping markers could also be developed [ $\underline{58}$, 59].

In the present investigation, five mutants (NN1-M-363, NN1-M-506, NN1-M-700, NN1-M-701 and NN1-M-1621) were selected from large mutant population of a wheat cultivar NN-Gandum$1(\mathrm{NN}-1)$. These mutants were subjected to exome capturing to detect SNPs relevant to drought resistance during $\mathrm{M}_{5}$ generation. The genetic diversity among wheat genotypes and drought tolerant mutant lines were further studied by applying different biochemical parameters for two years $\left(\mathrm{M}_{6}\right.$ and $\mathrm{M}_{7}$ generation). The information generated through these studies can be used for exploring the genetic circuits of drought tolerance in wheat which will help in improving drought tolerant wheat cultivars.

\section{Material and Methods:}

\section{Experimental Growth Conditions}

A high yielding wheat variety 'NN-Gandum-1', developed by the Plant Genomics and Molecular Breeding (PGMB) Lab, National Institute for Biotechnology and Genetic Engineering (NIBGE), Faisalabad, Pak, was selected for developing mutant population. The seed of this cultivar was 
exposed to an optimized concentration of $0.8 \%(\mathrm{v} / \mathrm{v})$ of ethyl methane sulphonate for $2 \mathrm{~h}$ at $35^{\circ} \mathrm{C}$. The seed were sterilized by performing three washings with 5\% sodium hypochlorite and 70\% ethanol to eradicate their residues. The procedure for developing the mutant population was described earlier [47]].

\section{Generation advancement and screening /selection of mutant lines}

The mutated population was advanced to $\mathrm{M}_{4}$ generation by raising single spike rows of $\mathrm{M}_{1}$ through $\mathrm{M}_{3}$. From planting to harvesting, recommended agronomic practices were applied to each generation. In total, 44 mutant lines were selected on the basis of their yield response and grown in randomized complete block design (RCBD) in three replicates under two water regimes i.e. well-watered conditions ( $\mathrm{W}_{1}$ regimes) i.e. four irrigations while other set was grown in rainfed conditions ( $\mathrm{W}_{2}$ regimes) i.e. $\sim 170 \mathrm{~mm}$ rainfall. In total, 24 high yielding mutant lines were selected on the basis of drought tolerance indices and advanced to $\mathrm{M}_{5}$ generation. The drought indices such as tolerance index (TOL), geometric mean productivity (GMP), mean productivity (MP), stress susceptibility index (SSI) and stress tolerance index (STI) were calculated by following formulas:

$$
\begin{aligned}
& T O L=Y P-Y S \ldots \ldots \ldots \ldots \ldots 1 \\
& M P=(Y P+Y S) / 2 \ldots \ldots \ldots . .2 \\
& G M P=\sqrt{Y S \times Y P} \ldots \ldots \ldots \ldots . .3 \\
& S T I=\frac{(Y P \times Y S)}{P^{2}} \ldots \ldots \ldots \ldots \ldots \ldots \ldots 4 \\
& S S I=\frac{\left\{1-\left(\frac{Y S}{Y P}\right)\right\}}{\left\{1-\left(\frac{S}{P}\right)\right\}} \ldots \ldots \ldots \ldots \ldots \ldots \ldots . . . \ldots
\end{aligned}
$$

Here, Ys and Yp represent grain yield under drought stress and normal condition respectively. Mean yield of all genotypes under normal condition is denoted as $\mathrm{P}$ and $\mathrm{S}$ indicates the mean yield of genotypes under stress.

\section{Physiological parameters}


These 24 mutant lines along with NN-1 (wild) were tested for physiological parameters such as photosynthetic absorbance rate (PAR) at leaf surface, sub-stomatal conductance, transpiration and photosynthetic rate under both the water regimes $\left(\mathrm{W}_{1}\right.$ and $\mathrm{W}_{2}$ regime). Data was recorded using LcPro-SD portable Photosynthetic System. A total of five mutant lines (NN1-M-363, NN1-M506, NN1-M-700, NN1-M-701 and NN1-M-1621) were selected on the basis of physiological parameters (Fig.1).

\section{Exome Capture assay:}

These selected mutants and their parent NN-1 (wild) were sown for isolation of a high quality DNA by adopting the protocol described by [으 w with few amendments. Genomic DNA concentration was measured with Nanodrop and normalized to $200 \mathrm{ng} / \mu \mathrm{l}$ by adding $(0.1 \mathrm{mM})$ EDTA, (10mM) Tris-HCl, maintained at $\mathrm{pH} 8$ and making solution of $130 \mu \mathrm{l}$ for every sample.

\section{Preparation of wheat exome captures libraries:}

The genomic DNA from individual samples were fragmented using Covaris E220 machine (UCD genome centre) for achieving the average fragment size $(250-450 \mathrm{bp})$. The fragmented DNA was end repaired using End Repair enzyme, after that A-tail and adapter was added to these DNA fragments using a KAPA's kit and Bioo Adapters (Sciclone G3 robot). The libraries with adapter ligation were exposed to Ampure beads for the size selection as per the selection protocol given in KAPA kits. Before hybridization, amplification step was completed for pre-capture of libraries with standard Nimblegen procedure. For each capture, five PCR cycles were performed. In total, $150 \mathrm{ng}$ of each library product and oligoes for each capture were pooled to make $1.2 \mu \mathrm{g}$ of total DNA for conducting hybridization. In a thermal cycler, hybridization was done for 68-72 hours outside of the robot (hybridization temperature was constant at $47^{\circ} \mathrm{C}$ and the lid was programmed for $57^{\circ} \mathrm{C}$ ). Then washed and recovered the captured hybrids. Using post capture primers, PCR was done for amplification of these captures. However, for quality check qPCR, Bioanalyzer was operated. Finally, for sequencing the pooled and final captured libraries with Illumina Hi-Seq 2000 (Illumina) were submitted to Beijing Genome Institute (BGI).

\section{Analysis and arrangement of mutant's reads against the wheat draft genome}


The sequence of each DNA fragment from start to stop codon was assessed using bioinformatic tools like Fastq software, 'bwaaln' and 'bwa sampe' programs, samtools and bamtools, MAPS (http://comailab.genomecenter.ucdavis.edu/index.php/MAPS) and 'mpileup' pipeline (http://comailab.genomecenter.ucdavis.edu/index.php/Mpileup). The real SNPs were differentiated from mutations by applying an additional MAPS feature. The homozygous and heterozygous threshold was setup independently. Using Ensembl Variant Effect Predictor (VEP) release 78 in offline mode, the effect of mutation on gene function were predicted and detected.

\section{Biochemical Assays:}

For assessment of drought resistance, selected mutants were further tested for studying their biochemical responses under both the regimes $\left(\mathrm{W}_{1}\right.$ and $\left.\mathrm{W}_{2}\right)$ for two consecutive normal wheat growing seasons.

Various biochemical parameters such as total soluble proteins (TSPs), total soluble sugars (TSSs), total free amino acids (TFAs), total chlorophyll contents, carotenoid contents, proline contents, enzymatic and non-enzymatic assays were analysed on $\mathrm{M}_{6}$ and $\mathrm{M}_{7}$ generations. For carrying out the aforementioned assays, fresh leaf samples were collected from the selected mutants and wild type in ice. The total TSPs ( $\mathrm{mg} \mathrm{g}^{-1} \mathrm{FW}$ ) were measured by following a published method [61]. In total, $0.5 \mathrm{~g}$ leaf tissues were homogenized into $10 \mathrm{ml}$ phosphate buffer $(0.2 \mathrm{M})$ and centrifuged at $4000 \mathrm{rpm}$ for five min. After centrifugation, $1 \mathrm{ml}$ supernatant was added into alkaline solution $(1 \mathrm{~mL})$ and then $0.5 \mathrm{ml}$ Folin-Phenol reagent (1:1 diluted) was added into the solution followed by the incubation of $30 \mathrm{~min}$ at room temperature. The optical density of the solution was measured at $620 \mathrm{~nm}$ using a spectrophotometer. Finally, the concentration of TSPs was estimated by comparing with the standard curve produced at various concentrations of bovine serum albumin (BSA).

For the determination of TSSs ( $\left.\mathrm{mg} \mathrm{g}^{-1} \mathrm{FW}\right)$, a protocol demonstrated by [드] was adopted. In total, $100 \mathrm{mg}$ leaf tissue was homogenized by adding $5 \mathrm{~mL}$ ethanol solution (80\%) and then incubated for six hours at $60^{\circ} \mathrm{C}$. A total volume of $6 \mathrm{~mL}$ anthrone reagent was added and the solution was boiled for $10 \mathrm{~min}$. The absorbance of the solution was recorded at $625 \mathrm{~nm}$ using a spectrophotometer. Finally, the sugar concentration was determined by comparing with a standard curve generated at different concentrations of glucose [63] . 
The TFAs (mg g-1 FW) were determined by adopting an assay described earlier [64]. A total of 0.5 $\mathrm{g}$ leaf tissue was added into $0.2 \mathrm{M}$ phosphate buffer. The reaction mixture was prepared by adding1 $\mathrm{mL}$ of each, leaf extract, pyridine (10\%), ninhydrin $(2 \%)$ and incubated for $30 \mathrm{~min}$. The absorbance was recorded at $570 \mathrm{~nm}$ using spectrophotometer and the concentration of TFAs was calculated by comparing with standard curve of leucine.

Total free amino acid $=($ Graph reading of sample $) \times($ Dilution Factor $) \ldots . . .6$

Dilution Factor $=($ Volume of sample/weight of sample $)$

For the calculation of total chlorophyll and carotenoid contents, the protocols described by [ $\underline{65}]$ and [66] were followed, respectively. In total, $0.5 \mathrm{~g}$ leaf tissue was homogenized into $5 \mathrm{ml}$ acetone $(80 \%)$ and the homogenate was centrifuged at $14000 \mathrm{rpm}$ for five min. Eventually, the absorbance was monitored at 480, 645, 652 and $663 \mathrm{~nm}$ with the help of spectrophotometer. Through deploying the following formulas, chlorophyll (Chla, $\mathrm{Chl}_{\mathrm{b}}, \mathrm{Chl}_{\mathrm{t}}$ ) and carotenoids contents were calculated:

$$
\begin{aligned}
& \mathrm{Chl}_{\mathrm{a}}\left(\mathrm{mg} \mathrm{g}^{-1} \mathrm{FW}\right)=[12.7(\mathrm{OD} 663)-2.69(\mathrm{OD} 645)] \times \frac{\mathrm{v}}{1000} \times \mathrm{W} \ldots \ldots \ldots \ldots . .8 \\
& \mathrm{Chl}_{\mathrm{b}}\left(\mathrm{mg} \mathrm{g}^{-1} \mathrm{FW}\right)=[22.9(\mathrm{OD} 645)-4.68(\mathrm{OD} 663)] \times \frac{\mathrm{V}}{1000} \times \mathrm{W} \ldots \ldots \ldots \ldots . .9 \\
& \text { Total } \mathrm{Chl}_{\mathrm{a}+\mathrm{b}}\left(\mathrm{mg} \mathrm{g}^{-1} \mathrm{FW}\right)=[20.2(\mathrm{OD} 645)+8.02(\mathrm{OD} 663)] \times \frac{\mathrm{V}}{1000} \times \mathrm{W} \ldots \ldots 10
\end{aligned}
$$

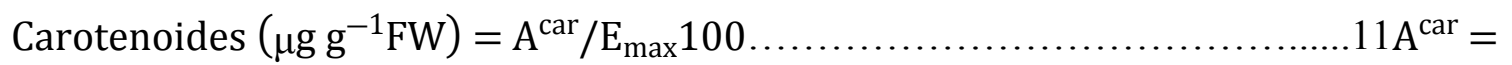$$
(\text { OD } 480)+0.114(\text { OD 663) }-0.638(\text { OD 645) } \ldots \ldots \ldots \ldots \ldots \ldots \ldots . \ldots 12
$$

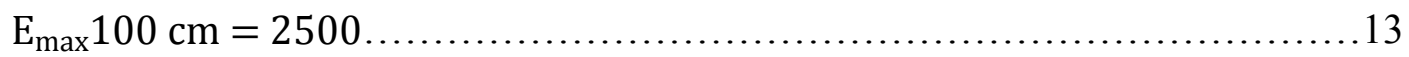

' $\mathrm{V}$ ' is the volume of extract and ' $\mathrm{W}$ ' is the weight of leaf sample

For the determination of proline contents (mmole $\left.\mathrm{g}^{-1} \mathrm{FW}\right)$, a published protocol was adopted [67]. A total of $0.5 \mathrm{~g}$ fresh leaf tissue was added into10 $\mathrm{mL}$ aqueous sulfo-salicylic acid (3\%) and filtered. In total, $2 \mathrm{~mL}$ of the filtrate was added into the solution containing $2 \mathrm{~mL}$ each of acid ninhydrin solution and glacial acetic acid. The solution was then incubated at $100^{\circ} \mathrm{C}$ for one hour, and the absorbance was determined at $520 \mathrm{~nm}$ through spectrophotometer. 
mmole proline $\mathrm{g}^{-1} \mathrm{FW}=\left[\frac{\left\{\left(\mathrm{mg} \text { of proline } \mathrm{mL}^{-1}\right) \mathrm{x}(\mathrm{mL} \text { of toluene })\right\}}{\mathrm{wt} \text { of } \frac{\text { sample }}{5}}\right] / 115 \ldots \ldots \ldots \ldots \ldots 14$

\section{Enzymatic Assays:}

Activity of superoxide dismutase (SOD, $\mu \mathrm{min}^{-1} \mathrm{mg}^{-1}$ ) was measured by deploying a protocol demonstrated earlier [68]. The photochemical reduction of nitro blue tetrazolium (NBT) is inhibited by SOD at $560 \mathrm{~nm}$ and this inhibition is used to assay SOD activity. The reaction mixture was prepared by mixing $0.95 \mathrm{~cm}^{3}$ phosphate buffer $(50 \mathrm{mM}), 0.5 \mathrm{~cm}^{3}$ methionine $(13 \mathrm{mM}), 1 \mathrm{~cm}^{3}$ NBT $(50 \mu \mathrm{M}), 0.5 \mathrm{~cm}^{3}$ EDTA $(75 \mathrm{mM}), 0.005$ riboflavin, enzyme extract $(50 \mu \mathrm{g} \mathrm{mL})$ and ionized $\mathrm{H}_{2} \mathrm{O}(0.25 \mathrm{ml})$. The solution was irradiated by a fluorescent lamp $(30 \mathrm{~V})$ for $15 \mathrm{~min}$. Afterwards, inhibition in photochemical activity of NBT and non-irradiated reaction were analyzed at $560 \mathrm{~nm}$, and were used to monitor the SOD activity.

The protocol devised by [요] was used to determine peroxidase activity (POD, $\mathrm{min}^{-1} \mathrm{~g}^{-1} \mathrm{FW}$ ). The reaction mixture consisted of phosphate buffer $(50 \mathrm{mM})$, guaiacol $(20 \mathrm{mM}), \mathrm{H}_{2} \mathrm{O}_{2}(40 \mathrm{mM})$ and enzyme extract $(0.1 \mathrm{~mL})$. POD activity was calculated by the estimation of the oxidation of guaiacol and peroxidation of $\mathrm{H}_{2} \mathrm{O}_{2}$ using an extinction coefficient of $2.47 \mathrm{mM}-1 \mathrm{~cm}-1$.

The catalase activity $\left(\mathrm{CAT}, \mathrm{min}^{-1} \mathrm{~g}^{-1} \mathrm{FW}\right)$ was measured by adopting a procedure described earlier [69]. The reaction mixture contained phosphate buffer $(50 \mathrm{mM}), \mathrm{H}_{2} \mathrm{O}_{2}(5.9 \mathrm{mM})$ and $0.1 \mathrm{~mL}$ enzyme extract in a volume of $3 \mathrm{~mL}$. The catalase activity was determined by the rate of $\mathrm{H}_{2} \mathrm{O}_{2}$ decomposition at $240 \mathrm{~nm}$ after every $20 \mathrm{sec}$.

The ascorbate peroxidase (APX, $\mathrm{g}^{-1} \mathrm{FW} \mathrm{h}^{-1}$ ) was quantified using the methodology proposed by [70]. The reaction mixture comprised of phosphate buffer $(50 \mathrm{mM})$, sodium-EDTA $(0.1 \mathrm{mM})$, $\mathrm{H}_{2} \mathrm{O}_{2}(12 \mathrm{mM})$, ascorbic acid $(0.25 \mathrm{mM})$ and sample extract in a total volume of $1 \mathrm{ml}$. The rate of ascorbate oxidation at $470 \mathrm{~nm}$ was monitored after every $20 \mathrm{sec}$ to measure APX activity. Finally, an extinction coefficient of $2.8 \mathrm{mM}-1 \mathrm{~cm}-1$ was used to calculate the APX activity.

\section{Non-Enzymatic Assays:}

For the detection of malondialdehyde contents (MDA, $\mu \mathrm{mol} \mathrm{g} \mathrm{g}^{-1} \mathrm{FW}$ ), a published protocol was followed [71]. In total, $1 \mathrm{~g}$ leaf tissue was added into $3 \mathrm{~cm}^{3}$ of trichloroacetic acid solution 
$(0.1 \% \mathrm{w} / \mathrm{v})$ and centrifuged at $20000 \mathrm{rpm}$ for $15 \mathrm{~min}$. The cocktail was made by adding $0.5 \mathrm{~cm}^{3}$ supernatant and $3 \mathrm{~cm}^{3}$ thiobarbituric acid (0.5\%) prepared in TCA (20\%). Then mixture was incubated for one hour at $95^{\circ} \mathrm{C}$ and centrifuged at $10000 \mathrm{rpm}$ for $10 \mathrm{~min}$. Final concentration of MDA was estimated by measuring the change in optical density of supernatant at $532 \mathrm{~nm}$ and 600 $\mathrm{nm}$ using extinction coefficient $\left(156 \mathrm{mmol}^{-1} \mathrm{~cm}^{-1}\right)$.

The hydrogen per oxide concentration $\left(\mathrm{H}_{2} \mathrm{O}_{2}, \mu \mathrm{mol} \mathrm{g}{ }^{-1} \mathrm{FW}\right)$ was measured by adopting a published protocol $[\underline{67}, \underline{72]}$. In total, $0.2 \mathrm{~g}$ leaf tissue was mixed into trichloroacetic acid solution and centrifuged at $10000 \mathrm{rpm}$ for $15 \mathrm{~min}$. After centrifugation, a volume of $500 \mathrm{ul}$ of each supernatant and potassium phosphate buffer $(10 \mathrm{mM})$ were mixed together and added $1 \mathrm{~mL}$ of potassium iodide solution (1 M). The absorbance was recorded at $390 \mathrm{~nm}$ and activity of the $\mathrm{H}_{2} \mathrm{O}_{2}$ was determined by comparing with the standard curve drawn from $\mathrm{H}_{2} \mathrm{O}_{2}$ (Sigma-Aldrich) via spectrophotometer.

\section{Statistical analysis:}

Analysis of variance (ANOVA) and least significant difference (LSD) for each trait was estimated using Statistix 8.1 and SPSS16 software [73]. The statistical significance was computed at 5\% probability.

\section{Results and Discussion}

Wheat is dominantly a drought loving plant, and mitigates the water limited conditions by bringing changes in its morphological, physiological and biochemical properties. In the present experiment, selected wheat mutants were exposed to limited water conditions for studying their physiological as well as biochemical changes and their impact on yield.

\section{Productivity traits data}

Increased grain yield of wheat is primary goal in drought affected areas. The use of drought resistant genotypes with higher yield is an effective approach to reduce harmful effects of drought [74]. In the present studies, significant differences were found for yield per unit area among the mutant lines grown under both the water regimes (well-watered, $\mathrm{W}_{1}$ and rain fed conditions, $\mathrm{W}_{2}$ ) at $\mathrm{p}<0.001$. Wheat yield ranged from $3016.07 \mathrm{~kg} \mathrm{ha}^{-1}$ to $5500.56 \mathrm{~kg} \mathrm{ha}^{-1}$ in $\mathrm{W}_{1}$ regime. While in $\mathrm{W}_{2}$ regime, wheat yield fluctuated between 2256.32 and $4965.32 \mathrm{~kg} \mathrm{ha}^{-1}$. Highest yield was depicted by NN1-M-451 with 9.73\% relative reduction (RR) under $\mathrm{W}_{2}$ regime. While the lowest yield was determined for NN1-M-320 with $25.19 \%$ RR under $\mathrm{W}_{2}$ regime (Table 1). Similar results 
of wheat yield reduction under drought stress were reported earlier [75]. To identify high yielding drought tolerant genotypes under both the normal and drought conditions, drought tolerance indices was used as screening criteria [므]. In previous studies, geometric mean productivity (GMP), mean productivity (MP) and stress tolerance index (STI) were found to be the most appropriate indexes for the identification of drought tolerant cultivars [77-79].

Table 1. Yield and yield-drought related indices of 44 mutant lines along with wild type NN-1 sown under $W_{1}$ and $W_{2}$ regime during $M_{4}$ generation 


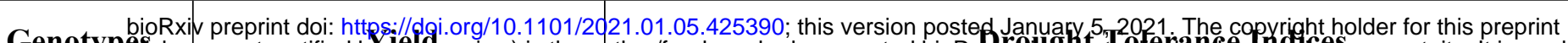

Genotypesch was not certified by

\begin{tabular}{|c|c|c|c|c|c|c|c|c|c|}
\hline Unit & $\begin{array}{c}\mathbf{W}_{1} \\
\text { regime }\end{array}$ & $\begin{array}{c}\mathrm{W}_{2} \\
\text { regime }\end{array}$ & $\mathbf{R R}$ & $\begin{array}{c}\text { Tolerance } \\
\text { Index }\end{array}$ & $\begin{array}{c}\text { Mean } \\
\text { Productivity }\end{array}$ & $\begin{array}{c}\text { Geometric } \\
\text { Mean } \\
\text { Productivity }\end{array}$ & $\begin{array}{c}\text { Stress } \\
\text { Tolerance } \\
\text { Index } \\
\end{array}$ & $\begin{array}{l}\text { Stress } \\
\text { Index }\end{array}$ & $\begin{array}{c}\text { Stress } \\
\text { Susceptibility } \\
\text { Index } \\
\end{array}$ \\
\hline Conditions & kg ha-1 & kg ha-1 & $\%$ & $\begin{array}{c}\text { TOL = } \\
\text { YP - YS }\end{array}$ & $\begin{array}{c}\mathbf{M P}=(\mathbf{Y P}+ \\
\mathbf{Y S}) / 2\end{array}$ & $\begin{array}{c}\text { GMP = } \\
\text { SQRT of } \\
(Y S \times Y P)\end{array}$ & $\begin{array}{c}\text { STI }= \\
(\text { YP } \times \\
\text { YS) } /(\mathbf{P}) \\
2\end{array}$ & $\begin{array}{r}\mathbf{S I}=\mathbf{1} \\
-(\mathbf{Y S} \\
/ \mathbf{Y P})\end{array}$ & $\begin{array}{c}\mathbf{S S I}=\mathbf{1}-(\mathbf{Y S} \\
/ \mathbf{Y P}) / \mathbf{1}-(\mathbf{S} \\
/ \mathbf{P})\end{array}$ \\
\hline Local Check-1 & 3639.47 & 2956.32 & -18.77 & 683.15 & 3297.895 & 3280.158 & 0.6121 & 0.1877 & 2.0553 \\
\hline Local Check-2 & 4711.35 & 3767.29 & -20.04 & 944.06 & 4239.32 & 4212.959 & 1.0097 & 0.2004 & 2.1941 \\
\hline NN1-M-1 & 3760.56 & 3554.26 & -5.49 & 206.3 & 3657.41 & 3655.955 & 0.7604 & 0.0549 & 0.6007 \\
\hline NN1-M-116 & 4359.29 & 4161.95 & -4.53 & 197.34 & 4260.62 & 4259.477 & 1.0321 & 0.0453 & 0.4957 \\
\hline NN1-M-118 & 4179.89 & 3708.98 & -11.27 & 470.91 & 3944.435 & 3937.401 & 0.8819 & 0.1127 & 1.2336 \\
\hline NN1-M-153 & 5224.87 & 4865.32 & -6.88 & 359.55 & 5045.095 & 5041.891 & 1.4461 & 0.0688 & 0.7535 \\
\hline NN1-M-158 & 4280.8 & 3537.44 & -17.37 & 743.36 & 3909.12 & 3891.410 & 0.8615 & 0.1736 & 1.9014 \\
\hline NN1-M-1621 & 3682.07 & 3558.74 & -3.35 & 123.33 & 3620.405 & 3619.880 & 0.7454 & 0.0335 & 0.3668 \\
\hline NN1-M-205 & 3285.16 & 3130.44 & -4.71 & 154.72 & 3207.8 & 3206.867 & 0.5850 & 0.0471 & 0.5157 \\
\hline NN1-M-2252 & 4585.77 & 4152.35 & -9.45 & 433.42 & 4369.06 & 4363.682 & 1.0832 & 0.0945 & 1.0349 \\
\hline NN1-M-236 & 4366.02 & 4043.11 & -7.4 & 322.91 & 4204.565 & 4201.464 & 1.0042 & 0.0740 & 0.8098 \\
\hline NN1-M-252 & 4004.98 & 3872.68 & -3.3 & 132.3 & 3938.83 & 3938.274 & 0.8823 & 0.0330 & 0.3617 \\
\hline NN1-M-277 & 4466.93 & 3872.68 & -13.3 & 594.25 & 4169.805 & 4159.206 & 0.9841 & 0.1330 & 1.4566 \\
\hline NN1-M-284 & 4058.8 & 3861.47 & -4.86 & 197.33 & 3960.135 & 3958.906 & 0.8916 & 0.0486 & 0.5323 \\
\hline NN1-M-285 & 3426.44 & 2982.44 & -12.96 & 444 & 3204.44 & 3196.741 & 0.5813 & 0.1296 & 1.4188 \\
\hline NN1-M-494 & 4314.44 & 3560.98 & -17.46 & 753.46 & 3937.71 & 3919.647 & 0.8740 & 0.1746 & 1.9122 \\
\hline NN1-M-338 & 4747.23 & 4096.92 & -13.7 & 650.31 & 4422.075 & 4410.104 & 1.1064 & 0.1370 & 1.4999 \\
\hline NN1-M-363 & 4415.35 & 4368.26 & -1.07 & 47.09 & 4391.805 & 4391.742 & 1.0972 & 0.0107 & 0.1168 \\
\hline NN1-M-370 & 3482.5 & 3125.32 & -10.26 & 357.18 & 3303.91 & 3299.080 & 0.6192 & 0.1026 & 1.1230 \\
\hline NN1-M-41 & 3996.01 & 3899.59 & -2.41 & 96.42 & 3947.8 & 3947.506 & 0.8865 & 0.0241 & 0.2642 \\
\hline NN1-M-411 & 4594.74 & 4415.35 & -3.9 & 179.39 & 4505.045 & 4504.152 & 1.1541 & 0.0390 & 0.4275 \\
\hline NN1-M-414 & 4500.56 & 4231.47 & -5.98 & 269.09 & 4366.015 & 4363.941 & 1.0834 & 0.0598 & 0.6547 \\
\hline NN1-M-430 & 3825.59 & 3679.83 & -3.81 & 145.76 & 3752.71 & 3752.002 & 0.8008 & 0.0381 & 0.4172 \\
\hline NN1-M-44 & 4789.84 & 4125.32 & -13.87 & 664.52 & 4457.58 & 4445.180 & 1.1241 & 0.1387 & 1.5191 \\
\hline NN1-M-451 & 5500.56 & 4965.32 & -9.73 & 535.24 & 5232.94 & 5226.092 & 1.5537 & 0.0973 & 1.0655 \\
\hline NN1-M-474 & 4588.02 & 3789.71 & -17.4 & 798.31 & 4188.865 & 4169.804 & 0.9891 & 0.1740 & 1.9052 \\
\hline NN1-M-490 & 4419.83 & 4110.38 & -7 & 309.45 & 4265.105 & 4262.298 & 1.0335 & 0.0700 & 0.7666 \\
\hline NN1-M-493 & 4601.47 & 3865.32 & -16 & 736.15 & 4233.395 & 4217.363 & 1.0118 & 0.1600 & 1.7517 \\
\hline NN1-M-320 & 3016.07 & 2256.32 & -25.19 & 759.75 & 2636.195 & 2608.681 & 0.3871 & 0.2519 & 2.7582 \\
\hline NN1-M-504 & 4386.62 & 3856.32 & -7.89 & 530.3 & 4121.47 & 4112.932 & 0.9623 & 0.1209 & 1.3237 \\
\hline NN1-M-506 & 4612.68 & 4487.11 & -2.72 & 125.57 & 4549.895 & 4549.462 & 1.1774 & 0.0272 & 0.2981 \\
\hline NN1-M-514 & 3330.01 & 2937.59 & -11.78 & 392.42 & 3133.8 & 3127.652 & 0.5565 & 0.1178 & 1.2903 \\
\hline NN1-M-535 & 4330.14 & 3774.01 & -12.84 & 556.13 & 4052.075 & 4042.523 & 0.9297 & 0.1284 & 1.4063 \\
\hline NN1-M-537 & 4610.44 & 3861.47 & -16.25 & 748.97 & 4235.955 & 4219.369 & 1.0128 & 0.1625 & 1.7788 \\
\hline NN1-M-60 & 3648.44 & 3392.8 & -7.01 & 255.64 & 3520.62 & 3518.299 & 0.7042 & 0.0701 & 0.7672 \\
\hline NN1-M-61 & 3569.95 & 3415.22 & -4.33 & 154.73 & 3492.585 & 3491.728 & 0.6936 & 0.0433 & 0.4746 \\
\hline NN1-M-628 & 4321.17 & 4231.47 & -2.08 & 89.7 & 4276.32 & 4276.085 & 1.0402 & 0.0208 & 0.2273 \\
\hline NN1-M-700 & 4224.74 & 4105.89 & -2.81 & 118.85 & 4165.315 & 4164.891 & 0.9868 & 0.0281 & 0.3080 \\
\hline
\end{tabular}




\begin{tabular}{|c|c|c|c|c|c|c|c|c|c|} 
NN1-M-701 & 4704.62 & 4566.86 & -2.93 & 137.76 & 4635.74 & 4635.228 & 1.2222 & 0.0293 & 0.3206 \\
\hline NN1-M-764 & 3993.77 & 3823.35 & -4.27 & 170.42 & 3908.56 & 3907.631 & 0.8686 & 0.0427 & 0.4672 \\
\hline NN1-M-827 & 4608.2 & 4361.53 & -5.35 & 246.67 & 4484.865 & 4483.169 & 1.1434 & 0.0535 & 0.5861 \\
\hline NN1-M-83 & 4027.41 & 3836.74 & -4.73 & 190.67 & 3932.075 & 3930.919 & 0.8790 & 0.0473 & 0.5184 \\
\hline NN1-M-85 & 4099.17 & 3832.32 & -6.51 & 266.85 & 3965.745 & 3963.500 & 0.8937 & 0.0651 & 0.7128 \\
\hline NN1-M-852 & 4253.89 & 3836.8 & -9.8 & 417.09 & 4045.345 & 4039.966 & 0.9285 & 0.0980 & 1.0736 \\
\hline NN1-M-88 & 4191.11 & 3256.32 & -22.3 & 934.79 & 3723.715 & 3694.265 & 0.7764 & 0.2230 & 2.4422 \\
\hline NN1-M-882 & 3269.47 & 2865.32 & -12.36 & 404.15 & 3067.395 & 3060.732 & 0.5329 & 0.1236 & 1.3535 \\
\hline NN1-M-parent & 4249.41 & 4102.32 & -3.46 & 147.09 & 4175.865 & 4175.217 & 0.9917 & 0.0346 & 0.3790 \\
\hline Mean & 4192.68 & 3809.77 & -9.13 & 387.167 & 4003.349 & 3996.499 & 0.9230 & 0.0926 & 1.0136 \\
\hline Max & 5500.56 & 4965.32 & -9.73 & 944.060 & 5232.940 & 5226.092 & 1.5537 & 0.2519 & 2.7582 \\
\hline Min & 3016.07 & 2256.32 & -25.19 & 47.090 & 2636.195 & 2608.681 & 0.3871 & 0.0107 & 0.1168 \\
\hline SD & 514.26 & 530.17 & 3.09 & 253.390 & 507.070 & 508.701 & 0.2273 & 0.0606 & 0.6635 \\
\hline SE & 75.074 & 77.398 & 3.09 & 36.961 & 73.964 & 74.202 & 0.0332 & 0.0088 & 0.0968 \\
\hline
\end{tabular}

It was reported earlier that genotypes having minimum tolerance index (TOL) and stress susceptibility index (SSI) values were least sensitive to drought and selection exclusively based upon these indices directs high yielding genotypes under drought conditions $[\underline{5}, \underline{75}, \underline{80}]$. In this study minimum TOL was calculated for NN1-M-363, NN1-M-628, NN1-M-41, NN1-M-700, NN1-M-1621 and NN1-M-506. While for SSI, NN1-M-363, NN1-M-628, NN1-M-41, NN1-M506, NN1-M-700 and NN1-M-701 depicted lowest values (Table 1). Under normal conditions, these genotypes demonstrated high yield while, under $\mathrm{W}_{2}$ regime their yield was reduced. The importance of the SSI was explained by [1] which and demonstrated that genotypes with less than one SSI value were tolerant to drought.

We selected 24 mutant lines which showed high MP and GMP values and minimum values for SSI and TOL as these were drought resistance and high yielding genotypes.

\section{Physiological parameters analysis:}

Photosynthesis, a primary metabolic process which determines crop production is affected by drought stress [르. In the current investigation, a total of 24 mutant lines having high yield were selected from $\mathrm{M}_{4}$ population. These mutant lines along with wild type were tested for physiological parameters such as photosynthetically active radiation (PAR) at leaf surface, sub-stomatal conductance $\left(\mathrm{g}_{\mathrm{s}}\right)$, transpiration rate $(\mathrm{E})$ and net photosynthetic rate $(\mathrm{Pn})$ under $\mathrm{W}_{1}$ and $\mathrm{W}_{2}$ regimes during $\mathrm{M}_{5}$ generation. Significant variation were found for all the physiological parameters among all the mutant lines under both water regimes at $\mathrm{p}<0.001$. Water stress caused prominent decrease 
in net photosynthetic rate $(\mathrm{Pn})$, sub-stomatal conductance (gs) and transpiration rate (E) in wheat and different crops $[\underline{34}, \underline{83}$. Under drought stress plant immediately closes stomata to maintain

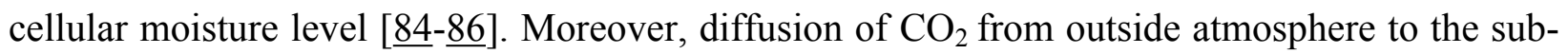
stomatal cavity is reduced, resultantly decrease the stomatal conductance $\left(\mathrm{g}_{\mathrm{s}}\right)$, and is the major reason of reduction in the photosynthetic rate $(\mathrm{Pn})$ during drought [4]. Some other studies have also reported reduction in net photosynthetic rate and sub-stomatal conductance in important crops during drought condition, such as in rice [87] and wheat [8].

In the present study, least relative reduction in PAR at leaf surface was observed for NN1-M-700 (4.2\%), NN1-M-701 (4.5\%), NN1-M-1621 (4.6\%) and NN1-M-363(5\%) as compared with wild type (5.1\%) under $\mathrm{W}_{2}$ regime (Fig 2). Regarding, sub-stomatal conductance minimum percentage reduction was recorded for NN1-M-506 (5.5\%), NN1-M-1621 (6.5\%), NN1-M-363 (7.2\%), and NN1-M-701 (7.8\%) compared to wild type (7.7\%) during water deficient condition. Similar findings of drought induced reduction were observed in stomatal conductance [89]. In case of transpiration rate a decrease of 4.6\% (NN1-M-363), 4.7\% (NN1-M-506), 5.1\% (wild type) and $5.5 \%$ (NN1-M- 700) was demonstrated. Reduction in transpiration rate were also reported in some other studies [83]. As far net photosynthetic rate is concerned, the mutants NN1-M-363 (10.93\%), NN1-M-701 (11.14\%) and NN1-M-700 (11.72\%) showed minimum percentage reduction (S1 Table). Reduced inhibition of net photosynthetic rate under limited water conditions is of great importance for drought tolerance [90].

\section{Fig 2. Identification of 5 mutants from 24 mutant lines on the base of physiological data}

Physiological data: PAR at leaf surface, substomatal conductance, transpiration rate and photosynthetic rate

On the basis of physiological parameters, five mutant lines i.e. NN1-M-363, NN1-M-506, NN1M-700, NN1-M-701 and NN1-M-1621 showing minimum reduction in PAR at leaf surface, net photosynthetic rate, sub-stomatal conductance and transpiration rate were selected for conducting exome capturing assays. 


\section{Exome capture assay}

The hexaploid wheat has relatively gigantic genome size of about $17.6 \mathrm{~GB}$, and it is difficult to identify mutations in such a large genome through using whole genome sequencing but exome capturing is one of the most suitable assays which can be exploited to detect mutations induced by EMS. By deploying exome sequencing, mutations can be detected in coding regions of a gene (exon) only which can alter the gene function and expression. The exome sequencing can be exploited for searching mutations in expressed part of the genes using multiple software including MAPS, VEP, etc. It is well known that fluctuations in genomes size are contributed by the nonexonic portions of the genome, thus exome size remains about the same in all plant species. Consequently, exome capture can be practiced in various crops regardless of the genome size and cost involved in conducting exome capture assay. This assay is extremely handy and economical for studying the genome of those species where reference genome assembly has not been constructed yet. We selected five mutant lines i.e. NN1-M-363, NN1-M-506, NN1-M-700, NN1M-701 and NN1-M-1621 on the basis of their response to drought. These mutants were exposed to exome capture assay for the identification of SNPs.

In total, 184 SNPs were identified in different genes which are involved in conferring drought tolerance. Overall, 96, 55, 14, 11 and 8 SNPs were detected in N1-M-701, NN1-M-700, NN1-M506, NN1-M-1621 and NN1-M-363, respectively (Table 2). The maximum number of SNPs both heterozygous and homozygous were observed in chr-2D (31 SNPs), however, few SNPs were found in chr-5D (7 SNPs) and chr-7B (3 SNPs). These SNPs dispersed on various wheat chromosomes are depicted in a Circos plot (Fig 3).

Fig 3. J-Circos Plot: First Circos plot indicates the size of exonic region of all wheat chromosome.

Graph bar in second circle shows dispersion of 184 SNPs on different chromosomes of wheat genome (A, B \& D). Lines in third circle indicates the distribution of SNPs on five wheat mutants i.e. Blue; NN1-M-363, Green; NN1-M-506, Yellow; NN1-M-700, Red; NN1-M-701 and Light blue; NN1-M-1621 
Table 2. SNPs detected in the selected mutants

\begin{tabular}{|c|c|c|c|c|c|c|c|}
\hline Chromosome & Genome & NN1-M-701 & NN1-M-700 & NN1-M-506 & NN1-M-1621 & NN1-M-363 & \# of SNPs \\
\hline \multirow[b]{3}{*}{1} & $\mathrm{~A}$ & 7 & 2 & 1 & 2 & 0 & 12 \\
\hline & $\mathrm{B}$ & 2 & 1 & 1 & 1 & 1 & 6 \\
\hline & $\mathrm{D}$ & 1 & 2 & 4 & 1 & 0 & 8 \\
\hline \multirow[b]{3}{*}{2} & $\mathrm{~A}$ & 4 & 14 & 0 & 2 & 1 & 21 \\
\hline & $\mathrm{B}$ & 9 & 3 & 0 & 1 & 4 & 17 \\
\hline & $\mathrm{D}$ & 20 & 10 & 1 & 0 & 0 & 31 \\
\hline \multirow[b]{3}{*}{3} & A & 2 & 0 & 2 & 0 & 0 & 4 \\
\hline & $\mathrm{B}$ & 2 & 8 & 1 & 0 & 0 & 11 \\
\hline & $\mathrm{D}$ & 2 & 3 & 2 & 0 & 0 & 7 \\
\hline \multirow[b]{3}{*}{4} & $\mathrm{~A}$ & 6 & 1 & 0 & 1 & 0 & 8 \\
\hline & $\mathrm{B}$ & 4 & 1 & 0 & 0 & 0 & 5 \\
\hline & $\mathrm{D}$ & 3 & 2 & 0 & 0 & 0 & 5 \\
\hline \multirow[b]{3}{*}{5} & $\mathrm{~A}$ & 4 & 0 & 0 & 0 & 0 & 4 \\
\hline & $\mathrm{B}$ & 9 & 1 & 0 & 0 & 0 & 10 \\
\hline & $\mathrm{D}$ & 5 & 0 & 0 & 1 & 1 & 7 \\
\hline \multirow[b]{3}{*}{6} & $\mathrm{~A}$ & 0 & 1 & 0 & 1 & 1 & 3 \\
\hline & $\mathrm{B}$ & 4 & 0 & 0 & 1 & 0 & 5 \\
\hline & $\mathrm{D}$ & 7 & 1 & 0 & 0 & 0 & 8 \\
\hline \multirow[b]{3}{*}{7} & A & 1 & 3 & 1 & 0 & 0 & 5 \\
\hline & $\mathrm{B}$ & 1 & 2 & 0 & 0 & 0 & 3 \\
\hline & D & 3 & 0 & 1 & 0 & 0 & 4 \\
\hline Total & & 96 & 55 & 14 & 11 & 8 & 184 \\
\hline
\end{tabular}

Though, chemical mutagenesis is a random process and many mutations are functionally silent. Also, the frequency of mutations in each site of the genome fluctuates substantially. Certainly, it was proved that if concentration of the mutagen remains same, the rate of mutation ranges from 120 mutations per $\mathrm{Mb}$ in diverse entities [91]. Yet, the total number of base pairs involved in the analysis varies by chromosome, followed by measuring the density of mutations. The maximum number of mutations were detected in chr.2D. However, minimum mutation density was identified in chr.6A, chr.5A, chr.7B and chr.7D. The mean mutation rate was 0.04 mutations/Mb (Table 3). 
Table 3. Frequency of mutation / Mb

\begin{tabular}{|c|c|c|c|}
\hline Chromosome & $\begin{array}{c}\text { Sequenced exon size } \\
\text { in each chromosome } \\
\text { (Mb) }\end{array}$ & \# of SNPs & $\begin{array}{c}\text { Number } \\
\text { of SNPs / } \\
\text { Mb }\end{array}$ \\
\hline 1A & 248 & 12 & 0.05 \\
\hline 1B & 295 & 6 & 0.02 \\
\hline 1D & 135 & 8 & 0.06 \\
\hline 2A & 255 & 21 & 0.08 \\
\hline 2B & 345 & 17 & 0.05 \\
\hline 2D & 150 & 31 & 0.21 \\
\hline 3A & 185 & 4 & 0.02 \\
\hline 3B & 124 & 11 & 0.09 \\
\hline 3D & 216 & 7 & 0.03 \\
\hline 4A & 317 & 8 & 0.03 \\
\hline 4B & 121 & 5 & 0.04 \\
\hline 4D & 148 & 5 & 0.03 \\
\hline 5A & 274 & 4 & 0.01 \\
\hline 5B & 162 & 10 & 0.06 \\
\hline 5D & 208 & 7 & 0.03 \\
\hline 6A & 204 & 3 & 0.01 \\
\hline 6B & 177 & 5 & 0.03 \\
\hline 6D & 182 & 8 & 0.04 \\
\hline 7A & 252 & 5 & 0.02 \\
\hline 7B & 238 & 3 & 0.01 \\
\hline 7D & 774 & 4 & 0.01 \\
\hline Mean mutation & 5010 & 184 & 0.04 \\
\hline
\end{tabular}

The main reasons of these fluctuations in mutation density owing to the variations in penetrability of EMS within seeds and the differential ability of the cell to repair the damaged DNA as shown in previous studies [44]. In several other studies, variation in normal density of mutation such as 19.6 mutations per $\mathrm{Mb}, 20.1$ mutations per $\mathrm{Mb}, 23$ mutations per $\mathrm{Mb}$ and 33 mutations per $\mathrm{Mb}$ were noticed in wheat $[52,91,92]$. In total, 121 mutations were reported in waxy genes in wheat, including silent, missense together with knockout by studying 2,348 EMS-mutated $\mathrm{M}_{2}$ plants [93]. Similarly, in four important genes i.e. LBP, COMIT1, HCT2, and 4CL1, SNPs were recognized. In TILLING population of polyploid wheat, the mutation frequency was one mutation per $17.6 \mathrm{~kb}$ 
to $34.4 \mathrm{~kb}$ mutations. However, in case of $T$. monococcum only one mutation per $90 \mathrm{~kb}$ was identified in waxy genes [며].

In the present studies, out of the 184 SNPs, 31 were induced in genes closely related to abiotic stresses particularly drought such as ABC transporter type 1, aspartic peptidase, cytochrome P450, transmembrane domain, heavy metal-associated domain, HMA, NAC domain, NAD(P)-binding domain, s-type anion channel, ubiquitin-conjugating enzyme E2 and UDP-glucuronosyl/UDPglucosyltransferase (Table 4).

Table 4: Gene Functions

\begin{tabular}{|c|c|c|c|}
\hline Genotypes & Genes & Functions & References \\
\hline NN1-M-701 & $\begin{array}{l}\mathrm{ABC} \text { transporter type } 1, \\
\text { transmembrane domain }\end{array}$ & $\begin{array}{l}\text { Regulate physiological } \\
\text { activities }\end{array}$ & --- \\
\hline NN1-M-1621 & Aspartic peptidase & $\begin{array}{l}\text { Plant senescence, stress } \\
\text { responses, programmed cell } \\
\text { death and reproduction }\end{array}$ & $\begin{array}{l}\text { Isaura and Carlos, } \\
2004\end{array}$ \\
\hline NN1-M-700 & & & \\
\hline NN1-M-701 & Cytochrome P450 & $\begin{array}{c}\text { protects plant from stresses, } \\
\text { establishment of complex } \\
\text { signaling webs }\end{array}$ & $\begin{array}{c}\text { Li et al., 2010; Jun et } \\
\text { al., 2015 }\end{array}$ \\
\hline NN1-M-700 & $\begin{array}{l}\text { Heavy metal-associated } \\
\text { domain, HMA }\end{array}$ & $\begin{array}{l}\text { Heavy metal transport and } \\
\text { detoxification, plays role } \\
\text { during drought, cold and salt } \\
\text { stress }\end{array}$ & $\begin{array}{l}\text { Barth et al., 2009; } \\
\text { Zschiesche et al., } \\
2015\end{array}$ \\
\hline NN1-M-700 & NAC domain & $\begin{array}{c}\text { Regulate biological processes, } \\
\text { biotic and abiotic stress } \\
\text { responses }\end{array}$ & $\begin{array}{l}\text { Zhao et al., 2015; } \\
\text { Chen et al., } 2018\end{array}$ \\
\hline NN1-M-700 & \multirow{4}{*}{ NAD(P)-binding domain } & \multirow{4}{*}{$\begin{array}{l}\text { Abiotic stresses, } \\
\text { developmental processes }\end{array}$} & \multirow{4}{*}{ Hashida et al., 2009} \\
\hline NN1-M-701 & & & \\
\hline NN1-M-1621 & & & \\
\hline NN1-M-363 & & & \\
\hline NN1-M-701 & S-type anion channel & $\begin{array}{l}\text { Regulate drought stress } \\
\text { responses }\end{array}$ & Murata et al., 2015 \\
\hline NN1-M-701 & $\begin{array}{l}\text { Ubiquitin-conjugating } \\
\text { enzyme E2 }\end{array}$ & $\begin{array}{l}\text { DNA repair, cell cycle } \\
\text { regulation, plant growth and } \\
\text { development }\end{array}$ & $\begin{array}{l}\text { Hochstrasser, M. } \\
\text { 2003; Gao et al., } \\
2017\end{array}$ \\
\hline NN1-M-700 & \multirow{2}{*}{$\begin{array}{l}\text { UDP-glucuronosyl/UDP- } \\
\text { glucosyltransferase }\end{array}$} & \multirow{2}{*}{$\begin{array}{l}\text { Drought stress tolerance, } \\
\text { seed germination }\end{array}$} & \multirow{2}{*}{ Liu et al., 2015} \\
\hline NN1-M-701 & & & \\
\hline
\end{tabular}


One mutation was observed in each of the $A B C$ transporter type 1, transmembrane domain, Aspartic peptidase, heavy metal-associated domain, HMA, NAC domain, S-type anion channel and Ubiquitin-conjugating enzyme E2 gene located on chr-2D of NN1-M-701 (114.5 Mb position), chr-2B of NN1-M-1621 (225.91 Mb position), chr-1A of NN1-M-700 (3.28 Mb position), chr-7B of NN1-M-700 (250.85 Mb position), chr-1B of NN1-M-701 (99.74 Mb position) and chr-1A of NN1-M-701 (3.88 Mb position) (Table 5). Similarly, four mutations were observed in Cytochrome P450 gene in NN1-M-700 and one in NN1-M-701. Likewise, four mutations in NN1-M-700, six in NN1-M-701, and one each in NN1-M-1621, and NN1-M-363 were observed in NAD $(P)$-binding domain gene. A total of six mutations in NN1-M-701 and two in NN1-M-700 were identified in UDP-glucuronosyl/UDP-glucosyltransferase gene (Table 5).

Table 5. SNPs detected in example gene

\begin{tabular}{|c|c|c|c|c|c|c|}
\hline Chromosome & $\begin{array}{l}\begin{array}{l}\text { Position } \\
\text { (Mbs) }\end{array} \\
\end{array}$ & Genotypes & $\begin{array}{l}\text { Protein } \\
\text { position }\end{array}$ & \begin{tabular}{|l} 
Amino \\
acids
\end{tabular} & Codons & Gene \\
\hline $2 \mathrm{D}$ & 114.50 & NN1-M-701 & 120 & $\mathrm{~A} / \mathrm{T}$ & Gcg/Acg & $\begin{array}{l}\mathrm{ABC} \text { transporter type } 1, \\
\text { transmembrane domain }\end{array}$ \\
\hline $2 \mathrm{~B}$ & 225.91 & \begin{tabular}{|l|} 
NN1-M-1621 \\
\end{tabular} & 116 & $\mathrm{R} / \mathrm{K}$ & $\mathrm{aGg} / \mathrm{aAg}$ & Aspartic peptidase \\
\hline $2 \mathrm{~A}$ & 27.95 & \multirow{4}{*}{ NN1-M-700 } & 347 & $\mathrm{~W} / *$ & $\operatorname{tgG} / \operatorname{tg} \mathrm{A}$ & \multirow{5}{*}{ Cytochrome P450 } \\
\hline $2 \mathrm{~A}$ & 7.50 & & 171 & $\mathrm{R} / \mathrm{K}$ & $\mathrm{aGg} / \mathrm{aAg}$ & \\
\hline $2 \mathrm{~A}$ & 7.50 & & 434 & $\mathrm{~S} / \mathrm{N}$ & $\mathrm{aGt} / \mathrm{aAt}$ & \\
\hline $3 \mathrm{~B}$ & 89.37 & & 98 & $\mathrm{G} / \mathrm{S}$ & $\mathrm{Ggc} / \mathrm{Agc}$ & \\
\hline $5 \mathrm{~B}$ & 114.32 & NN1-M-701 & 281 & $\mathrm{R} / \mathrm{H}$ & $\mathrm{cGc} / \mathrm{cAc}$ & \\
\hline $1 \mathrm{~A}$ & 3.28 & NN1-M-700 & 88 & $\mathrm{~V} / \mathrm{M}$ & Gtg/Atg & $\begin{array}{l}\text { Heavy metal-associated } \\
\text { domain, HMA }\end{array}$ \\
\hline $7 \mathrm{~B}$ & 250.85 & NN1-M-700 & 283 & $\mathrm{~W} / *$ & $\operatorname{tg} \mathrm{G} / \operatorname{tg} \mathrm{A}$ & NAC domain \\
\hline $1 \mathrm{~A}$ & 2.18 & \multirow{4}{*}{ NN1-M-700 } & 174 & $\mathrm{G} / \mathrm{S}$ & $\mathrm{Ggc} / \mathrm{Agc}$ & \multirow{12}{*}{$\mathrm{NAD}(\mathrm{P})$-binding domain } \\
\hline $2 \mathrm{D}$ & 9.90 & & 76 & V/I & $\mathrm{Gtt} / \mathrm{Att}$ & \\
\hline $2 \mathrm{D}$ & 41.48 & & 17 & G/D & $\mathrm{gGc} / \mathrm{gAc}$ & \\
\hline $3 \mathrm{~B}$ & 9.98 & & 252 & $\mathrm{M} / \mathrm{I}$ & atG/atA & \\
\hline $1 \mathrm{D}$ & 2.22 & \multirow{6}{*}{ NN1-M-701 } & 133 & $\mathrm{~A} / \mathrm{T}$ & Gca/Aca & \\
\hline $2 \mathrm{D}$ & 9.87 & & 55 & $\mathrm{~A} / \mathrm{T}$ & Gca/Aca & \\
\hline $2 \mathrm{D}$ & 134.47 & & 195 & $\mathrm{C} / \mathrm{Y}$ & $\mathrm{tGc} / \mathrm{tAc}$ & \\
\hline 4D & 65.06 & & 740 & $\mathrm{E} / \mathrm{K}$ & Gaa/Aaa & \\
\hline $4 \mathrm{D}$ & 65.06 & & 780 & $\mathrm{E} / \mathrm{K}$ & Gaa/Aaa & \\
\hline $6 \mathrm{~B}$ & 2.44 & & 115 & $\mathrm{E} / \mathrm{K}$ & Gag/Aag & \\
\hline $2 \mathrm{~A}$ & 14.18 & NN1-M-1621 & 949 & $\mathrm{G} / \mathrm{D}$ & $\mathrm{gGc} / \mathrm{gAc}$ & \\
\hline $6 \mathrm{~A}$ & 4.39 & NN1-M-363 & 51 & $\mathrm{~A} / \mathrm{T}$ & Gca/Aca & \\
\hline $1 \mathrm{~B}$ & 99.74 & NN1-M-701 & 161 & $\mathrm{Q} / *$ & $\mathrm{caG} / \operatorname{tgA}$ & S-type anion channel \\
\hline
\end{tabular}




\begin{tabular}{|c|c|c|c|c|c|c|}
\hline $1 \mathrm{~A}$ & 3.88 & NN1-M-701 & 192 & G/D & $\mathrm{gGt} / \mathrm{gAt}$ & $\begin{array}{l}\text { Ubiquitin-conjugating } \\
\text { enzyme E2 }\end{array}$ \\
\hline $2 \mathrm{~A}$ & 7.14 & \multirow{2}{*}{ NN1-M-700 } & 258 & $\mathrm{G} / \mathrm{S}$ & Ggc/Agc & \multirow{8}{*}{$\begin{array}{l}\text { UDP-glucuronosyl/UDP- } \\
\text { glucosyltransferase }\end{array}$} \\
\hline $2 \mathrm{D}$ & 3.84 & & 2 & G/D & $\mathrm{gGt} / \mathrm{gAt}$ & \\
\hline $2 \mathrm{~B}$ & 9.40 & \multirow{6}{*}{ NN1-M-701 } & 248 & $\mathrm{G} / \mathrm{R}$ & Ggg/Agg & \\
\hline $2 \mathrm{~B}$ & 274.25 & & 166 & $\mathrm{G} / \mathrm{S}$ & $\mathrm{Ggc} / \mathrm{Agc}$ & \\
\hline $2 \mathrm{D}$ & 3.84 & & 50 & $\mathrm{R} / \mathrm{H}$ & $\mathrm{cGc} / \mathrm{cAc}$ & \\
\hline $5 B$ & 191.93 & & 321 & $\mathrm{E} / \mathrm{K}$ & Gag/Aag & \\
\hline $5 \mathrm{D}$ & 154.00 & & 35 & $\mathrm{D} / \mathrm{N}$ & $\mathrm{Gac} / \mathrm{Aac}$ & \\
\hline $6 \mathrm{D}$ & 140.48 & & 83 & G/D & $\mathrm{gGc} / \mathrm{gAc}$ & \\
\hline
\end{tabular}

\section{D protein structure:}

The SNP identified in chimeric allele (heavy metal-associated domain, HMA) of a drought resistant mutant (NN1-M-700) was located in HMA domain of chr.1A at $3.28 \mathrm{Mb}$ position. Through computational analysis, it was demonstrated that this SNP causes a substitution of valine with methionine, resulting in a predicted altered protein structure (Fig 4). This mutation, therefore, is a candidate for contributing to the resistance phenotype in the mutant line.

\section{Fig 4. 3D protein structure of single copy gene HMA identified in genotype NN1-M-700}

\section{Biochemical assays:}

\section{Total Soluble Proteins (TSPs):}

The TSPs play a vital role in cellular dehydration tolerance in wheat and their accumulation in leaves helps in mitigating dehydration [도-96]. The current study indicated that drought stress significantly decreased the total soluble proteins in both generations $\left(\mathrm{M}_{6}\right.$ and $\left.\mathrm{M}_{7}\right)$ of wheat. In $\mathrm{M}_{6}$ generation, NN1-M-363 and NN1-M-1621 exhibited 35 and 33\% reduction in TSPs, respectively (S2 Table). While NN1-M-506 and NN1-M-701 showed less reduction in TSPs in both the generations under drought conditions (Fig 5). The decline in soluble proteins during dehydration might be linked with the decrease in protein biosynthesis [97]. In another study, soluble proteins were reduced after the exposure of drought stress in tomato and sorghum [98]. This indicates reduction in protein synthesis is due to its breakage to amino acids under water limited conditions. Contrary to the present study, synthesis of protein in plants was increased under stress condition regulated by endogenous cytokinins and eventually promoting drought tolerance [99]. 


\section{Fig 5. Total Soluble Proteins (TSPs) in NN-Gandum-1 genotypes}

At two conditions: well-watered (control, $\mathrm{W}_{1}$ regime) and rainfed (stressed, $\mathrm{W}_{2}$ regime). Values presented are means \pm S.D of three replicates per genotype in both $\mathrm{M}_{6}$ and $\mathrm{M}_{7}$ generation. Different color indicates stress condition, blue bar for $\mathrm{W}_{1}$-well watered (control) and grey bar for $\mathrm{W}_{2}$-rainfed (stressed) conditions

\section{Total Soluble Sugars (TSSs):}

Wheat plant accumulates high level of soluble sugars for mitigating water deficit. These sugars are synthesized during photosynthesis and act as substrate for carbon and energy metabolism in plants [100]. Soluble sugars work as osmoprotectants for leaf osmotic adjustment and protect the cells from dehydration [101]. A significant increase in soluble sugars in leaf during drought stress was observed in German chamomile (Matricaria chamomilla L.) [102]. In present investigation, soluble sugars have been increased by desiccation in both the generations (Fig 6). Wheat genotype NN1-M-701 showed highest increase, i.e. $64 \%$ and $69 \%$ in $M_{6}$ and $M_{7}$ generations, respectively (S2 Table). Such an increase in soluble sugar contents were also observed in common bermudagrass under limited water conditions [피].

Fig 6. Total Soluble Sugars (TSSs) in NN-Gandum-1 genotype under well-watered (control, $\mathrm{W}_{1}$ regime) and rainfed (stressed, $\mathrm{W}_{2}$ regime) conditions

Values presented are means \pm S.D of three replicates per genotype in both $\mathrm{M}_{6}$ and $\mathrm{M}_{7}$ generation. Different color indicates stress condition, blue bar for $\mathrm{W}_{1}$-well watered (control) and grey bar for $\mathrm{W}_{2}$-rainfed (stressed) conditions

\section{Total Free Amino Acid (TFAs):}

TFAs inhibit the production of reactive oxygen species (ROS) and regulate stomata, and defend macromolecules to maintain cellular water balance under drought stress. Free amino acids and sugars contents can be used as an essential selection criterion for drought tolerance [34]. In the current investigation, a remarkable increase in total free amino acid was recorded for all the mutants in both the generations $\left(\mathrm{M}_{6}\right.$ and $\mathrm{M}_{7}$ ) (Fig 7). During $\mathrm{M}_{6}$ generation, $72 \%$ increase was demonstrated for NN1-M-506. While next year, 75\% and 76\% increase in TFAs were estimated for NN1-M-701 and NN1-M-506 respectively. Total free amino acids were accumulated more in 
$\mathrm{M}_{7}$ as compared to $\mathrm{M}_{6}$ generation. However, relatively less accumulation of free TFAs was observed in NN1-M-1621 under rainfed condition (Table S2). These results are in accordance with the earlier studies [103-104]. The increase in TFAs in present study indicates that stress tolerance in mutants resulted from the detoxification of ROS and perform functional role as compatible osmolyte.

Fig 7. Total Free Amino Acids (TFAs) in NN-Gandum-1 genotype under well-watered (control, $W_{1}$ regime) and rainfed (stressed, $W_{2}$ regime) conditions

Values presented are means \pm S.D of three replicates per genotype in both $\mathrm{M}_{6}$ and $\mathrm{M}_{7}$ generation. Different color indicates stress condition, blue bar for $\mathrm{W}_{1}$-well watered (control) and grey bar for $\mathrm{W}_{2}$-rainfed (stressed) conditions

\section{Total Chlorophyll Contents:}

Drought limits the photosynthesis by retarding the synthesis of photosynthetic pigments. It is well established fact that chlorophyll contents and photosynthetic rate are positively correlated $[\underline{105}$, 106]. In the present study, NN1-M-wild depicted $17 \%$ reduction in chlorophyll content while NN1M-506 recorded 22\% during $\mathrm{M}_{7}$ generation (Fig 8; Table S2). Photosynthetic pigments production reduces under drought stress because of splitting of thylakoid membranes due to desiccation of cells [107]. The drought-resistant varieties produce these pigments in abundance under drought stress [107-109]. The synthesis of chlorophyll content repressed due to water deficiency, resultantly produced ROS, and eventually caused lipid peroxidation. Physiological traits of wheat genotypes studied under rainfed conditions had high chlorophyll contents that help in improved seed production during dehydration [110-113].

Fig 8. Total Chlorophyll Contents in NN-Gandum-1 genotype under well-watered (control, $\mathrm{W}_{1}$ regime) and rainfed (stressed, $\mathrm{W}_{2}$ regime) conditions

Values presented are means \pm S.D of three replicates per genotype in both $\mathrm{M}_{6}$ and $\mathrm{M}_{7}$ generation. Different color indicates stress condition, blue bar for $\mathrm{W}_{1}$-well watered (control) and grey bar for $\mathrm{W}_{2}$-rainfed (stressed) conditions 


\section{Carotenoid Contents:}

A dynamic part is played by carotenoid contents to scavenge oxygen, hence, the relative quantity of carotenoid in plants approves the comparative tolerance of plant to stress. In the current experiment, maximum reduction in carotenoid content was observed in genotypes NN1-M-506 and NN1-M-701 in $\mathrm{M}_{6}$ generation. However, NN1-wild demonstrated 20\% reduction during the first growing season while 36\% reduction was recorded in the second growing season (Fig 9; S2 Table). In another study, stress tolerant varieties accumulated higher chlorophyll as well as carotenoid contents $[\underline{114}, \underline{115}]$. The amounts of pigments reduced with constant increase in drought stress and the genotypes having increased contents of chlorophyll during dehydration are considered as drought tolerant $[\underline{90}, \underline{113}]$. The production of carotenoid contents is affected by the genetics of the plant as well as the prevailing environments [116].

Fig 9. Carotenoid Contents in NN-Gandum-1 genotype under well-watered (control, $\mathrm{W}_{1}$ regime) and rainfed (stressed, $W_{2}$ regime) conditions

Values presented are means \pm S.D of three replicates per genotype in both $\mathrm{M}_{6}$ and $\mathrm{M}_{7}$ generation. Different color indicates stress condition, blue bar for $\mathrm{W}_{1}$-well watered (control) and grey bar for $\mathrm{W}_{2}$-rainfed (stressed) condition 


\section{Proline Contents:}

The proline synthesis escalates in response to drought stress [117-119]. Accretion of proline in wheat leaves sustains osmotic pressure of the cell [120] linked with decrease in oxidative stress and high photosynthetic ability [121-124].

In the present study, water stress induced proline contents accumulation in all mutants (Fig 10). Maximum increase (75\%) was recorded for NN1-M-701, followed by 73\% in each of NN1-M-506 and wild type during $\mathrm{M}_{7}$ generation. The wheat genotype NN1-M-701, also depicted maximum increase of $76 \%$ during $\mathrm{M}_{6}$ generation (S2 Table). Proline plays a vital role in membrane stability [125] as it diminishes the effects of stress by scavenging free radicals. As a signal regulator molecule, it employs many strategies that assist in mitigating drought stress [126]. Similar findings expressing the enhanced synthesis of proline under drought conditions were demonstrated in earlier studies [127, 128]. However, NN1-M-363, NN1-M-700 and NN1-M-1621 did not show significant reduction in proline contents during rainfed conditions (Fig 10).

\section{Fig 10. Proline Contents in NN-Gandum-1 genotype under well-watered (control, $W_{1}$ regime) and rainfed (stressed, $W_{2}$ regime) conditions}

Values presented are means \pm S.D of three replicates per genotype in both $\mathrm{M}_{6}$ and $\mathrm{M}_{7}$ generation. Different color indicates stress condition, blue bar for $\mathrm{W}_{1}$-well watered (control) and grey bar for $\mathrm{W}_{2}$-rainfed (stressed) conditions

\section{Superoxide dismutase (SOD) Activity:}

The SOD protects from the activity of ROS in plants [129]. It has the ability of affecting superoxide radicals, catalyses and converts $\mathrm{O}_{i 2}$ to $\mathrm{O}_{2}$, and $\mathrm{H}_{2} \mathrm{O}_{2}[\underline{28}, \underline{130}, \underline{131}]$. In previous experiments, an increase in SOD activity was observed in plants facing abiotic stresses, like water deficiency and toxic metal effects $[\underline{132}, \underline{133}]$. The current results showed an increase in SOD activity in wheat mutants under rainfed conditions. In NN1-M-506 an increase of 35\% in SOD activity was estimated during water stress in $M_{6}$ generation while in $M_{7}$ the activity was $41 \%$ (Fig 11). The SOD activity could be used as potential selection strategy for screening drought-resistant plants [134]. Thus NN1-M-506 could be used as a drought tolerant genotype in future wheat breeding experiments. 
Fig 11. SOD activity in NN-Gandum-1 genotype under well-watered (control, $\mathrm{W}_{1}$ regime) and rainfed (stressed, $W_{2}$ regime) conditions

Values presented are means \pm S.D of three replicates per genotype in both $\mathrm{M}_{6}$ and $\mathrm{M}_{7}$ generation. Different color indicates stress condition, blue bar for $\mathrm{W}_{1}$-well watered (control) and grey bar for $\mathrm{W}_{2}$-rainfed (stressed) conditions

\section{Catalase (CAT) Activity:}

Catalase enzymes has an essential role in modulation of ROS in plant cells by deactivation of hydrogen peroxide $\left(\mathrm{H}_{2} \mathrm{O}_{2}\right)$ [135]. During water limited conditions, CAT regulates harmful levels of endogenous $\mathrm{H}_{2} \mathrm{O}_{2}$ by catalysing a redox reaction within cell peroxisomes [28, $\left.\underline{136}\right]$. In the current investigation, $21 \%$ and 20\% increase in CAT activity was observed in NN1-M-506 and NN1-M-701, respectively under rainfed conditions in $\mathrm{M}_{6}$ generation (Fig 12). The same trend was observed in $\mathrm{M}_{7}$ for both the genotypes, confirming that these mutants could be useful source for studying drought tolerance mechanism (S2 Table). Likewise, an increase in catalase activities was noticed in wheat leaves when exposed to extreme water stress, particularly more insusceptible varieties [12].

Fig 12. CAT activity in NN-Gandum-1 genotype under well-watered (control, $\mathrm{W}_{1}$ regime) and rainfed (stressed, $W_{2}$ regime) conditions

Values presented are means \pm S.D of three replicates per genotype in both $\mathrm{M}_{6}$ and $\mathrm{M}_{7}$ generation. Different color indicates stress condition, blue bar for $\mathrm{W}_{1}$-well watered (control) and grey bar for $\mathrm{W}_{2}$-rainfed (stressed) conditions

\section{Ascorbate peroxidase (APX) Activity:}

In the present study, 40\% increase in APX activity was observed in NN1-M-701 in $\mathrm{M}_{7}$ generation while during $\mathrm{M}_{6}$ generation 23\% increase was recorded (Fig 13). Furthermore, NN1-M-506 and NN1-M-wild also revealed improvement in APX activity. Likewise,, increase in APX activity during drought stress was reported by [137]. Hence, ascorbate peroxidases are the vital enzymes 
in plant cells that scavenge $\mathrm{H}_{2} \mathrm{O}_{2}$ in different organelle of plant cells as in chloroplast and cytosol to protect against oxidative damage [130].

\section{Fig 13. APX activity in NN-Gandum-1 genotype under well-watered (control, $\mathrm{W}_{1}$ regime) and rainfed (stressed, $W_{2}$ regime) conditions}

Values presented are means \pm S.D of three replicates per genotype in both $\mathrm{M}_{6}$ and $\mathrm{M}_{7}$ generation.

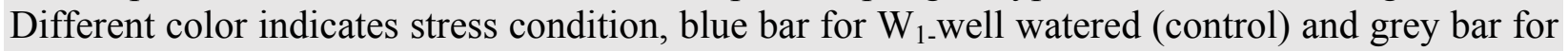
$\mathrm{W}_{2}$-rainfed (stressed) conditions

\section{Specific Peroxiodase (POD) Activity:}

Reactive oxygen species production in water deficient cells results in cell damage ultimately leads towards cell death [138]. Various antioxidant systems through multiple adaptive mechanisms regulate oxidative stress, one of them is peroxidase enzyme whose activity was increased under moderate level of water deficit [31]. In the present investigations, 77\% increase in peroxidase activity under limited water conditions was observed in NN1-M-701 during $\mathrm{M}_{7}$ generation. Owing to the rise in specific peroxidase activity during drought condition, the most affected mutant was NN1-M-700 depicting 31\% increase in peroxidase activity. The NN1-M-701and NN1-M-506 were observed as highly reactive showing elevated peroxidase activity during drought stress, however, NN1-M-700 showed minimum increase in both generations (Fig 14).

Fig 14. POD activity in NN-Gandum-1 genotype under well-watered (control, $\mathrm{W}_{1}$ regime) and rainfed (stressed, $W_{2}$ regime) conditions

Values presented are means \pm S.D of three replicates per genotype in both $\mathrm{M}_{6}$ and $\mathrm{M}_{7}$ generation. Different color indicates stress condition, blue bar for $\mathrm{W}_{1}$-well watered (control) and grey bar for $\mathrm{W}_{2}$-rainfed (stressed) conditions

The enhanced expression of peroxidase in a cell is linked with more water retention and thus rewarding tolerance to drought as it was demonstrated in Nicotiana tabacum. Like many other crop species, peroxidase activity was increased in wheat under water limited conditions $[\underline{139}, \underline{140}]$. The POD is present in cytosol, vacuoles, extracellular spaces and cell walls. This enzyme is well thought stress indicator which has a wide range of selectivity for phenolic substrates and more 
attraction for $\mathrm{H}_{2} \mathrm{O}_{2}$ than that of catalase. It has the ability to utilize $\mathrm{H}_{2} \mathrm{O}_{2}$ in order to generate phenoxy compounds which ultimately polymerizes lignin (cell wall component) [141]. Increased POD activity revealed in the present study can be associated with the release of peroxidase localized in the cell walls [136].

\section{Malondialdehyde (MDA)contents:}

The malondialdehyde production in plants is stimulated by free radicles [142]. Membrane lipid peroxidation was evaluated with the production of MDA content that indicates the degree of membrane damage under stress. In this experiment enhancement in MDA content in all mutant genotypes was recorded (Fig 15). Maximum increase (44\%) was noticed in NN1-M-701 likewise genotype NN1-M-506, also demonstrated significant increase (40\%) under drought stress. A positive relationship was found among the amount of MDA and demolition of biological membranes. This suggests that increase in MDA contents, results in more lipid peroxidation and higher cell deterioration [143]. These findings have shown that under water deficit, the oxidative damage in leaves of NN1-M-701 and NN1-M -506 was greater than that of NN1-M-363, NN1-M700 and NN1-M-1621 (S2 Table). In some other findings, higher MDA contents under water stress conditions were demonstrated, however, drought-susceptible and drought-tolerant genotypes expressed differential responses $[\underline{126}, \underline{144}, \underline{145}]$. Moreover, the drought tolerant wheat genotype demonstrated reduction in lipid peroxidation and greater membrane stability [146].

\section{Fig 15. MDA contents in NN-Gandum-1 genotype under well-watered (control, $\mathrm{W}_{1}$ regime) and rainfed (stressed, $W_{2}$ regime) conditions}

Values presented are means \pm S.D of three replicates per genotype in both $\mathrm{M}_{6}$ and $\mathrm{M}_{7}$ generation. Different color indicates stress condition, blue bar for $\mathrm{W}_{1}$-well watered (control) and grey bar for $\mathrm{W}_{2}$-rainfed (stressed) conditions

\section{$\mathrm{H}_{2} \mathrm{O}_{2}$ Activity:}

The $\mathrm{H}_{2} \mathrm{O}_{2}$ is a stress predictor of water deficit conditions in plants. It regulates respiratory pathways [147, 148]. Similarly, wheat plant protects leaves from oxidative stress by activating the antioxidant defense system. The mutant NN1-M-701 depicted the maximum increase 58\% and $47 \%$ of $\mathrm{H}_{2} \mathrm{O}_{2}$ contents in $\mathrm{M}_{6}$ and $\mathrm{M}_{7}$ generations, respectively. Furthermore, in $\mathrm{M}_{6}$ generation, 
NN1-wild and NN1-M-506 demonstrated 49\% and 53\% increase in $\mathrm{H}_{2} \mathrm{O}_{2}$, respectively (Fig 16; S2 Table). Likewise, in $\mathrm{M}_{7}$ generation all the mutant genotypes displayed positive response. Multiple factors such as plant species, stress intensity and plant growth decide the $\mathrm{H}_{2} \mathrm{O}_{2}$ detoxification by an antioxidant enzyme [149]. During drought stress, $\mathrm{H}_{2} \mathrm{O}_{2}$ scavenges the ROS by activating enzymatic antioxidant defense mechanisms in wheat [150]. These findings are in close conformity that $\mathrm{H}_{2} \mathrm{O}_{2}$ is a stress marker that regulates the antioxidants to decrease the damage under oxidative stress [151].

Fig 16. $\mathrm{H}_{2} \mathrm{O}_{2}$ Activity in NN-Gandum-1 genotype under well-watered (control, $\mathrm{W}_{1}$ regime) and rainfed (stressed, $W_{2}$ regime) conditions

Values presented are means \pm S.D of three replicates per genotype in both $\mathrm{M}_{6}$ and $\mathrm{M}_{7}$ generation. Different color indicates stress condition, blue bar for $\mathrm{W}_{1}$-well watered (control) and grey bar for $\mathrm{W}_{2}$-rainfed (stressed) conditions

\section{Conclusion:}

In the present study, it was analysed that genes relevant to agronomically significant traits can be improved via induced mutations. Also, the mutations induced in functionally important part of the gene can be identified using NGS based exome capturing assay, a strategy to save time and cost without compromising the significant mutations. This work also highlighted the distribution pattern, variation in frequency of mutation in different mutant lines of wheat. Based on the current investigations, it can be suggested that mutant wheat population NN-Gandum-1 is suitable for exploring the genetic circuits of several genetic mechanisms using forward and reverse-genetic approaches. The mutants were also explored using various biochemical and physiological assays, and showed significant variations under rainfed conditions. Hence this population can be used by the international wheat community for designing new strategies for mitigating drought stress.

\section{Acknowledgements}

The funds for developing wheat mutant were provided by the International Atomic Energy Commission (IAEA), Vienna, Austria through a project entitled "Developing Germplasm through 
TILLING in Crop Plants Using Mutation and Genomic Approaches (PAK/5/047). Special appreciations are extending to Dr Cristobal Uauy, Project Leader Crop Genetics, John Innes Centre, Norwich Research Park, UK for providing lab facility for undertaking exome capture assay and analysis. I am also extremely grateful to Pakistan Agriculture Research Council (PARC) for providing funds to take this project to logical end through a project entitled "Characterization of mutants derived from EMS-derived Gandum-1 for rust and drought tolerance for sustaining wheat yield in Pakistan" (CS 049) under ALP scheme.

\section{References:}

1. Abhinandan K, Skori L, Stanic M, Hickerson NM, Jamshed M, Samuel MA. Abiotic Stress Signaling in Wheat-An Inclusive Overview of Hormonal Interactions During Abiotic Stress Responses in Wheat. Front Plant Sci. 2018;9.

2. Chen L, Huang L, Min D, Phillips A, Wang S, Madgwick PJ, et al. Development and characterization of a new TILLING population of common bread wheat (Triticum aestivum L.). PLOS ONE. 2012;7(7):e41570.

3. Halford NG, Curtis TY, Chen Z, Huang J. Effects of abiotic stress and crop management on cereal grain composition: implications for food quality and safety. J Exp Bot. 2015;66(5):114556.

4. Mendanha T, Rosenqvist E, Nordentoft Hyldgaard B, Doonan JH, Ottosen CO. Drought priming effects on alleviating the photosynthetic limitations of wheat cultivars (Triticum aestivum L.) with contrasting tolerance to abiotic stresses. J Agron Crop Sci. 2020.

5. Anwaar HA, Perveen R, Mansha MZ, Abid M, Sarwar ZM, Aatif HM, et al. Assessment of grain yield indices in response to drought stress in wheat (Triticum aestivum L.). Saudi J Biol Sci. 2020;27(7):1818-23.

6. Trethowan RM, van Ginkel M, Rajaram S. Progress in breeding wheat for yield and adaptation in global drought affected environments. Crop Sci. 2002;42(5):1441-6. 
7. Godfray HCJ, Beddington JR, Crute IR, Haddad L, Lawrence D, Muir JF, et al. Food security: the challenge of feeding 9 billion people. Science. 2010;327(5967):812-8.

8. Noya I, González-García S, Bacenetti J, Fiala M, Moreira MT. Environmental impacts of the cultivation-phase associated with agricultural crops for feed production. J Clean Prod. 2018;172:3721-33.

9. Seiler C, Harshavardhan VT, Reddy PS, Hensel G, Kumlehn J, Eschen-Lippold L, et al. Abscisic acid flux alterations result in differential abscisic acid signaling responses and impact assimilation efficiency in barley under terminal drought stress. Plant Physiol. 2014;164(4):167796.

10. Tabarzad A, Ayoubi B, Riasat M, Saed-Moucheshi A, Pessarakli M. Perusing biochemical antioxidant enzymes as selection criteria under drought stress in wheat varieties. J Plant Nutr. 2017;40(17):2413-20.

11. Sallam A, Alqudah AM, Dawood MF, Baenziger PS, Börner A. Drought stress tolerance in wheat and barley: advances in physiology, breeding and genetics research. Int J Mol Sci. 2019;20(13):3137.

12. Simova-Stoilova L, Vaseva I, Grigorova B, Demirevska K, Feller U. Proteolytic activity and cysteine protease expression in wheat leaves under severe soil drought and recovery. Plant Physiol Biochem. 2010;48(2-3):200-6.

13. Conway G. The doubly green revolution: food for all in the twenty-first century: Cornell University Press; 1998.

14. Bakhshandeh S, Corneo PE, Yin L, Dijkstra FA. Drought and heat stress reduce yield and alter carbon rhizodeposition of different wheat genotypes. J Agron Crop Sci. 2019;205(2):157-67. 15. Senapati N, Stratonovitch P, Paul MJ, Semenov MA. Drought tolerance during reproductive development is important for increasing wheat yield potential under climate change in Europe. J Exp Bot. 2019;70(9):2549-60.

16. Nezhadahmadi A, Prodhan ZH, Faruq G. Drought tolerance in wheat. Sci World J. 2013;2013.

17. Khan S, Anwar S, Yu S, Sun M, Yang Z, Gao Z-q. Development of drought-tolerant transgenic wheat: achievements and limitations. Int J Mol Sci. 2019;20(13):3350.

18. Munns R. Genes and salt tolerance: bringing them together. New Phytol. 2005;167(3):64563. 
19. Iqbal MJ. Role of osmolytes and antioxidant enzymes for drought tolerance in wheat. Global Wheat Production. 2018;51.

20. Touzy G, Rincent R, Bogard M, Lafarge S, Dubreuil P, Mini A, et al. Using environmental clustering to identify specific drought tolerance QTLs in bread wheat (T. aestivum L.). Theor Appl Genet. 2019;132(10):2859-80.

21. Senapati N, Semenov MA. Large genetic yield potential and genetic yield gap estimated for wheat in Europe. Glob Food Sec. 2020;24:100340.

22. Reynolds M, Mujeeb-Kazi A, Sawkins M. Prospects for utilising plant-adaptive mechanisms to improve wheat and other crops in drought-and salinity-prone environments. Ann Appl Biol. 2005;146(2):239-59.

23. Mwadzingeni L, Shimelis H, Dube E, Laing MD, Tsilo TJ. Breeding wheat for drought tolerance: Progress and technologies. J Integr Agric. 2016;15(5):935-43.

24. You J, Chan Z. ROS regulation during abiotic stress responses in crop plants. Front Plant Sci. 2015;6:1092.

25. Passioura J. Phenotyping for drought tolerance in grain crops: when is it useful to breeders? Funct Plant Biol. 2012;39(11):851-9.

26. Hasanuzzaman M, Nahar K, Anee T, Khan M, Fujita M. Silicon-mediated regulation of antioxidant defense and glyoxalase systems confers drought stress tolerance in Brassica napus L. South Afr J Bot. 2018;115:50-7.

27. Miller G, Suzuki N, Ciftci-Yilmaz S, Mittler R. Reactive oxygen species homeostasis and signalling during drought and salinity stresses. Plant Cell Environ. 2010;33(4):453-67.

28. Sharma P, Jha AB, Dubey RS, Pessarakli M. Reactive oxygen species, oxidative damage, and antioxidative defense mechanism in plants under stressful conditions. J Bot. 2012;2012.

29. Huseynova IM, Rustamova SM, Suleymanov SY, Aliyeva DR, Mammadov AC, Aliyev JA. Drought-induced changes in photosynthetic apparatus and antioxidant components of wheat (Triticum durum Desf.) varieties. Photosynth Res. 2016;130(1-3):215-23.

30. Pandey S, Fartyal D, Agarwal A, Shukla T, James D, Kaul T, et al. Abiotic stress tolerance in plants: myriad roles of ascorbate peroxidase. Front Plant Sci. 2017;8:581.

31. Manuchehri R, Salehi H. Physiological and biochemical changes of common bermudagrass (Cynodon dactylon [L.] Pers.) under combined salinity and deficit irrigation stresses. South Afr J Bot. 2014;92:83-8. 
32. Khalilzadeh R, Seyed Sharifi R, Jalilian J. Antioxidant status and physiological responses of wheat (Triticum aestivum L.) to cycocel application and bio fertilizers under water limitation condition. J Plant Interact. 2016;11(1):130-7.

33. Ren R, Li Z, Zhang L, Zhou H, Jiang X, Liu Y. Enzymatic and nonenzymatic antioxidant systems impact the viability of cryopreserved Paeonia suffruticosa pollen. Plant Cell Tissue Organ Cult. 2020:1-14.

34. Farooq M, Wahid A, Kobayashi N, Fujita D, Basra S. Plant drought stress: effects, mechanisms and management. Sustainable agriculture: Springer; 2009. p. 153-88.

35. Scheibe R, Beck E. Drought, desiccation, and oxidative stress. Plant desiccation tolerance: Springer; 2011. p. 209-31.

36. Huseynova IM. Photosynthetic characteristics and enzymatic antioxidant capacity of leaves from wheat cultivars exposed to drought. Biochimica et Biophysica Acta (BBA)Bioenergetics. 2012;1817(8):1516-23.

37. Caverzan A, Casassola A, Brammer SP. Antioxidant responses of wheat plants under stress. Genet Mol Biol. 2016;39(1):1-6.

38. Khan A, Hassan S, Tariq M, Khan T. Haploidy breeding and mutagenesis for drought tolerance in wheat. Mutations, In Vitro and Molecular Techniques for Environmentally Sustainable Crop Improvement: Springer; 2002. p. 75-82.

39. Sharma A, Zheng B. Melatonin mediated regulation of drought stress: physiological and molecular aspects. Plants. 2019;8(7):190.

40. Singh R, Tiwari R, Sharma D, Tiwari V, Sharma I. Mutagenesis for wheat improvement in the genomics era. J Wheat Res. 2014;6:120-5.

41. Suprasanna P, Mirajkar S, Patade V, Jain SM. Induced mutagenesis for improving plant abiotic stress tolerance. Mutagenesis: exploring genetic diversity of crops Wageningen Academic Publishers, Wageningen. 2014:345-76.

42. Ponce-Molina LJ, Huerta-Espino J, Singh RP, Basnet BR, Lagudah E, Aguilar-Rincón VH, et al. Characterization of Adult Plant Resistance to Leaf Rust and Stripe Rust in Indian Wheat Cultivar 'New Pusa 876'. Crop Sci. 2018.

43. Mba C, Afza R, Bado S, Jain SM. Induced mutagenesis in plants using physical and chemical agents. Plant cell culture: essential methods. 2010;20:111-30. 
44. Hussain M, Iqbal MA, Till BJ. Identification of induced mutations in hexaploid wheat genome using exome capture assay. PLOS ONE. 2018;13(8):e0201918.

45. Brini F, Masmoudi K. Biotechnology for Drought and Salinity Tolerance of Crops. Physiological Mechanisms and Adaptation Strategies in Plants Under Changing Environment: Springer; 2014. p. 97-113.

46. Hussain M, Rahman M. Registration of PGMB-15-30 Spring Wheat. J of Plant Regist. 2019. doi: 10.3198/jpr2018.03.0015crg.

47. Hussain M, Iqbal MA, Till BJ, Rahman M. Identification of induced mutations in hexaploid wheat genome using exome capture assay. PLOS ONE. 2018;13(8):e0201918.

48. Zhang X, Chen X, Wu Z, Huang C, Cao M. A dwarf wheat mutant is associated with increased drought resistance and altered responses to gravity. Afr J Biotechnol. 2005;4(10).

49. Sinclair TR. Challenges in breeding for yield increase for drought. Trends Plant Sci. 2011;16(6):289-93.

50. Zhang J, Chiodini R, Badr A, Zhang G. The impact of next-generation sequencing on genomics. J Genet Genom. 2011;38(3):95-109.

51. Jia M, Guan J, Zhai Z, Geng S, Zhang X, Mao L, et al. Wheat functional genomics in the era of next generation sequencing: an update. Crop J. 2018;6(1):7-14.

52. Krasileva KV, Vasquez-Gross HA, Howell T, Bailey P, Paraiso F, Clissold L, et al. Uncovering hidden variation in polyploid wheat. Proceedings of the National Academy of Sciences. 2017;114(6):E913-E21.

53. Tsai H, Missirian V, Ngo KJ, Tran RK, Chan SR, Sundaresan V, et al. Production of a high-efficiency TILLING population through polyploidization. Plant Physiol. 2013;161(4):160414.

54. Schneeberger K. Using next-generation sequencing to isolate mutant genes from forward genetic screens. Nat Rev Genet. 2014;15(10):662-76.

55. Mo Y, Howell T, Vasquez-Gross H, De Haro LA, Dubcovsky J, Pearce S. Mapping causal mutations by exome sequencing in a wheat TILLING population: a tall mutant case study. Mol Genet Genomics. 2018;293(2):463-77.

56. Hodges E, Xuan Z, Balija V, Kramer M, Molla MN, Smith SW, et al. Genome-wide in situ exon capture for selective resequencing. Nat Genet. 2007;39(12):1522-7. 
57. Saintenac C, Jiang D, Akhunov ED. Targeted analysis of nucleotide and copy number variation by exon capture in allotetraploid wheat genome. Genome Biol. 2011;12(9):R88.

58. Mascher M, Jost M, Kuon J-E, Himmelbach A, Aßfalg A, Beier S, et al. Mapping-bysequencing accelerates forward genetics in barley. Genome Biol. 2014;15(6):R78.

59. Rimbert H, Darrier B, Navarro J, Kitt J, Choulet F, Leveugle M, et al. High throughput SNP discovery and genotyping in hexaploid wheat. PLOS ONE. 2018;13(1):e0186329.

60. Dvorak J, McGuire PE, Cassidy B. Apparent sources of the A genomes of wheats inferred from polymorphism in abundance and restriction fragment length of repeated nucleotide sequences. Genome. 1988;30(5):680-9.

61. Classics Lowry O, Rosebrough N, Farr A, Randall R. Protein measurement with the Folin phenol reagent. J Biol Chem. 1951;193:265-75.

62. Yemm E, Willis A. The estimation of carbohydrates in plant extracts by anthrone. Biochem J. 1954;57(3):508-14.

63. Fales FW. The assimilation and degradation of carbohydrates by yeast cells. J Biol Chem. $1951 ; 193(1): 113-24$.

64. Hamilton P, Van Slyke D. Amino acid determination with ninhydrin. J Biol Chem. 1943;150(1):231-50.

65. Arnon DI. Copper enzymes in isolated chloroplasts. Polyphenoloxidase in Beta vulgaris. Plant Physiol. 1949;24(1):1.

66. Davies W, Metcalfe J, Lodge T, da Costa AR. Plant growth substances and the regulation of growth under drought. Funct Plant Biol. 1986;13(1):105-25.

67. Bates LS, Waldren RP, Teare I. Rapid determination of free proline for water-stress studies. Plant Soil. 1973;39(1):205-7.

68. Chance B, Maehly AC. Assay of catalase and pemxides. Methods Enzymol. 1955;2:76475.

69. Giannopolitis CN, Ries SK. Superoxide dismutases: I. Occurrence in higher plants. Plant Physiol. 1977;59(2):309-14.

70. Cakmak I. Activity of ascorbate-dependent $\mathrm{H}_{2} \mathrm{O}_{2}$-scavenging enzymes and leaf chlorosis are enhanced in magnesium-and potassium-deficient leaves, but not in phosphorus-deficient leaves. J Exp Bot. 1994;45(9):1259-66. 
71. Cakmak I, Horst WJ. Effect of aluminium on lipid peroxidation, superoxide dismutase, catalase, and peroxidase activities in root tips of soybean (Glycine max). Physiologia Plantarum. 1991;83(3):463-8.

72. Velikova V, Yordanov I, Edreva A. Oxidative stress and some antioxidant systems in acid rain-treated bean plants: protective role of exogenous polyamines. Plant Sci. 2000;151(1):59-66.

73. Inc S. The SPSS TwoStep Cluster component: A scalable component enabling more efficient customer segmentation. Technical report. SPSS, Chicago, IL, 2001.

74. Haque M, Chowdhury S. Trend of irrigation water requirement in Halda river basin of Bangladesh. J Sci Technol Environ Inform. 2020;10(01):673-84.

75. Khakwani AA, Dennett M, Munir M, Abid M. Growth and yield response of wheat varieties to water stress at booting and anthesis stages of development. Pak J Bot. 2012;44(3):87986.

76. Mohammed A, Kadhem F. Screening drought tolerance in bread wheat genotypes (Triticum aestivum L.) using drought indices and multivariate analysis. Iraqi J Agric Sci. 2017;48:41.

77. Nouraein M, Mohammadi SA, Aharizad S, Moghaddam M, Sadeghzadeh B. Evaluation of drought tolerance indices in wheat recombinant inbred line population. Ann Biol Res. 2013;4(3):113-22.

78. Mohammadijoo M, Kenny S, Wiskel J, Ivey D, Henein H, editors. Cold-wire tandem submerged arc welding: A novel technique for pipeline manufacturing. 54th Anuual Conf Metall, Canadian Institute of Mining, Metallurgy and Petroleum, Toronto, ON; 2015.

79. Mohammadi R. Efficiency of yield-based drought tolerance indices to identify tolerant genotypes in durum wheat. Euphytica. 2016;211(1):71-89.

80. Dorostkar S, Dadkhodaie A, Heidari B. Evaluation of grain yield indices in hexaploid wheat genotypes in response to drought stress. Arch Agron Soil Sci. 2015;61(3):397-413.

81. Fischer R, Maurer R. Drought resistance in spring wheat cultivars. I. Grain yield responses. Aust J Agric Res. 1978;29(5):897-912.

82. Chaves MM, Flexas J, Pinheiro C. Photosynthesis under drought and salt stress: regulation mechanisms from whole plant to cell. Ann Bot. 2009;103(4):551-60.

83. Zhao W, Liu L, Shen Q, Yang J, Han X, Tian F, et al. Effects of water stress on photosynthesis, yield, and water use efficiency in winter wheat. Water. 2020;12(8):2127. 
84. Flexas J, Barón M, Bota J, Ducruet J-M, Gallé A, Galmés J, et al. Photosynthesis limitations during water stress acclimation and recovery in the drought-adapted Vitis hybrid Richter-110 (V. berlandieri $\times$ V.rupestris). J Exp Bot. 2009;60(8):2361-77.

85. Mondini L, Pagnotta MA. Drought and salt stress in cereals. Sustain Agric Rev: Springer; 2015. p. 1-31.

86. Osakabe Y, Osakabe K, Shinozaki K, Tran L-SP. Response of plants to water stress. Front Plant Sci. 2014;5:86.

87. Wang X, Du T, Huang J, Peng S, Xiong D. Leaf hydraulic vulnerability triggers the decline in stomatal and mesophyll conductance during drought in rice. J Exp Bot. 2018;69(16):4033-45.

88. Marček T, Hamow KÁ, Végh B, Janda T, Darko E. Metabolic response to drought in six winter wheat genotypes. PLOS ONE. 2019;14(2):e0212411.

89. Yan W, Zhong Y, Shangguan Z. A meta-analysis of leaf gas exchange and water status responses to drought. Sci Rep. 2016;6:20917.

90. Liu B, An G, Gao X. Morpho-physiological responses of Alhagi sparsifolia Shap.(leguminosae) seedlings to progressive drought stress. Pak J Bot. 2016;48(2):429-38.

91. Henry IM, Nagalakshmi U, Lieberman MC, Ngo KJ, Krasileva KV, Vasquez-Gross H, et al. Efficient genome-wide detection and cataloging of EMS-induced mutations using exome capture and next-generation sequencing. Plant Cell. 2014;26(4):1382-97.

92. Uauy C, Paraiso F, Colasuonno P, Tran RK, Tsai H, Berardi S, et al. A modified TILLING approach to detect induced mutations in tetraploid and hexaploid wheat. BMC Plant Biol. 2009;9(1):115.

93. Dong C, Dalton-Morgan J, Vincent K, Sharp P. A modified TILLING method for wheat breeding. Plant Genome. 2009;2(1):39-47.

94. Rawat N, Sehgal SK, Joshi A, Rothe N, Wilson DL, McGraw N, et al. A diploid wheat TILLING resource for wheat functional genomics. BMC Plant Biol. 2012;12(1):205.

95. Basu S, Ramegowda V, Kumar A, Pereira A. Plant adaptation to drought stress. F1000 Research. 2016;5.

96. Khalid A, Hameed A. Seed biochemical analysis based profiling of diverse wheat genetic resource from Pak. Front Plant Sci. 2017;8:1276. 
97. Rodriguez D, Romero-García J, Rodríguez-García R, Angulo-Sanchez J. Characterization of proteins from sunflower leaves and seeds: relationship of biomass and seed yield. Trends in new crops and new uses ASHS Press, Alexandria, VA. 2002:143-9.

98. Chandra A, Anand A, Dubey A. Effect of salicylic acid on morphological and biochemical attributes in cowpea. J Environ Biol. 2007;28(2):193-6.

99. Merewitz EB, Gianfagna T, Huang B. Protein accumulation in leaves and roots associated with improved drought tolerance in creeping bentgrass expressing an ipt gene for cytokinin synthesis. J Exp Bot. 2011;62(15):5311-33.

100. W. Patrick J, C. Botha F, G. Birch R. Metabolic engineering of sugars and simple sugar derivatives in plants. Plant Biotechnol J. 2013;11(2):142-56.

101. Guo Y, Yu H, Yang M, Kong D, Zhang Y. Effect of drought stress on lipid peroxidation, osmotic adjustment and antioxidant enzyme activity of leaves and roots of Lycium ruthenicum Murr. seedling. Russ J Plant Physiol. 2018;65(2):244-50.

102. Salehi A, Tasdighi H, Gholamhoseini M. Evaluation of proline, chlorophyll, soluble sugar content and uptake of nutrients in the German chamomile (Matricaria chamomilla L.) under drought stress and organic fertilizer treatments. Asian Pac J Trop Biomed. 2016;6(10):886-91.

103. Noreen S, Fatima K, Athar H, Ahmad S, Hussain K. Enhancement of physio-biochemical parameters of wheat through exogenous application of salicylic acid under drought stress. J Anim Plant Sci. 2017;27(1):153-63.

104. Selim DA-FH, Nassar RMA, Boghdady MS, Bonfill M. Physiological and anatomical studies of two wheat cultivars irrigated with magnetic water under drought stress conditions. Plant Physiol Biochem. 2019;135:480-8.

105. Arunyanark A, Jogloy S, Akkasaeng C, Vorasoot N, Kesmala T, Nageswara Rao R, et al. Chlorophyll stability is an indicator of drought tolerance in peanut. J Agron Crop Sci. 2008;194(2):113-25.

106. Dawood MF, Abeed AH, Aldaby EE. Titanium dioxide nanoparticles model growth kinetic traits of some wheat cultivars under different water regimes. Plant Physiol Rep. 2019;24(1):12940 .

107. Kalaji HM, Jajoo A, Oukarroum A, Brestic M, Zivcak M, Samborska IA, et al. Chlorophyll a fluorescence as a tool to monitor physiological status of plants under abiotic stress conditions. Acta physiologiae plantarum. 2016;38(4):102. 
108. Zhang M, Lv D, Ge P, Bian Y, Chen G, Zhu G, et al. Phosphoproteome analysis reveals new drought response and defense mechanisms of seedling leaves in bread wheat (Triticum aestivum L.). J Proteom. 2014;109:290-308.

109. Epée Missé PT. Wheat Seedling Physiological Adaptation to Overcome Water Stress. Available at SSRN 3307427. 2018.

110. Alaei Y. The effect of amino acids on leaf chlorophyll content in bread wheat genotypes under drought stress conditions. Middle-East J Sci Res. 2011;10(1):99-101.

111. Arjenaki FG, Jabbari R, Morshedi A. Evaluation of drought stress on relative water content, chlorophyll content and mineral elements of wheat (Triticum aestivum L.) varieties. Int J Agric Crop Sci. 2012;4(11):726-9.

112. Ahmed K, Shabbir G, Ahmed M, Shah KN. Phenotyping for drought resistance in bread wheat using physiological and biochemical traits. Sci Total Environ. 2020:139082.

113. Farshadfar E, Amiri R. Genetic analysis of physiological indicators of drought tolerance in bread wheat using diallel technique. Genetika. 2015;47(1):107-18.

114. LICHTENTHALER HK, Wellburn AR. Determinations of total carotenoids and chlorophylls a and b of leaf extracts in different solvents. Portland Press Ltd.; 1983.

115. Livingston DP, Hincha DK, Heyer AG. Fructan and its relationship to abiotic stress tolerance in plants. Cell Mol Life Sci. 2009;66(13):2007-23.

116. Bollinedi H, Dhakane-Lad J, Krishnan SG, Bhowmick P, Prabhu K, Singh N, et al. Kinetics of $\beta$-carotene degradation under different storage conditions in transgenic Golden Rice ${ }^{\circledR}$ lines. Food Chem. 2019;278:773-9.

117. Bajji M, Lutts S, Kinet J-M. Water deficit effects on solute contribution to osmotic adjustment as a function of leaf ageing in three durum wheat (Triticum durum Desf.) cultivars performing differently in arid conditions. Plant Sci. 2001;160(4):669-81.

118. Arias-Baldrich C, Bosch N, Begines D, Feria AB, Monreal JA, García-Mauriño S. Proline synthesis in barley under iron deficiency and salinity. J Plant Physiol. 2015;183:121-9.

119. Ullah A, Manghwar H, Shaban M, Khan AH, Akbar A, Ali U, et al. Phytohormones enhanced drought tolerance in plants: a coping strategy. Environ Sci Pollut Res. 2018;25(33):33103-18.

120. Zadehbagheri M, Azarpanah A, Javanmardi S. Proline metabolite transport an efficient approach in corn yield improvement as response to drought conditions. Nat. 2014;566:76-485. 
121. Farshadfar E. Incorporation of AMMI stability value and grain yield in a single nonparametric index (GSI) in bread wheat. Pak J Biol Sci. 2008;11(14):1791.

122. Ghahremani M, Ghanati F, Bernard F, Azad T, Gholami M, Safari M. Ornithine-induced increase of proline and polyamines contents in tobacco cells under salinity conditions. Aust J Crop Sci. 2014;8(1):91.

123. Iqbal SZ, Mustafa HG, Asi MR, Jinap S. Variation in vitamin E level and aflatoxins contamination in different rice varieties. J Cereal Sci. 2014;60(2):352-5.

124. Raza M, Saleem M, Shah G, Khan I, Raza A. Exogenous application of glycinebetaine and potassium for improving water relations and grain yield of wheat under drought. J Soil Sci Plant Nutr. 2014;14(2):348-64.

125. Bandurska H, Gorny A, Zielezinska M. Effects of water deficit on the relative water content, proline accumulation and injury of cell membranes in leaves of old and modern cultivars of winter wheat. Zeszyty Problemowe Postępów Nauk Rolniczych. 2008;(524).

126. Marcińska I, Czyczyło-Mysza I, Skrzypek E, Filek M, Grzesiak S, Grzesiak MT, et al. Impact of osmotic stress on physiological and biochemical characteristics in drought-susceptible and drought-resistant wheat genotypes. Acta physiologiae plantarum. 2013;35(2):451-61.

127. Quilambo O. Proline content, water retention capability and cell membrane integrity as parameters for drought tolerance in two peanut cultivars. South Afr J Bot. 2004;70(2):227-34.

128. Slabbert M, Krüger G. Antioxidant enzyme activity, proline accumulation, leaf area and cell membrane stability in water stressed Amaranthus leaves. South Afr J Bot. 2014;95:123-8.

129. Noctor G, Reichheld J-P, Foyer CH, editors. ROS-related redox regulation and signaling in plants. Seminars in Cell \& Developmental Biology; 2018: Elsevier.

130. Strukul G. Catalytic oxidations with hydrogen peroxide as oxidant: Springer Sci \& Business Media; 2013.

131. Quartacci MF, Sgherri CL, Pinzino C, Navari-Izzo F. Superoxide radical production in wheat plants differently sensitive to drought. Proceedings of the Royal Society of Edinburgh, Section B: Biological Sciences. 1994;102:287-90.

132. Sharma P, Dubey RS. Drought induces oxidative stress and enhances the activities of antioxidant enzymes in growing rice seedlings. Plant Growth Regul. 2005;46(3):209-21. 
133. Mishra S, Jha A, Dubey R. Arsenite treatment induces oxidative stress, upregulates antioxidant system, and causes phytochelatin synthesis in rice seedlings. Protoplasma. 2011;248(3):565-77.

134. Zaefyzadeh M, Quliyev RA, Babayeva SM, Abbasov MA. The effect of the interaction between genotypes and drought stress on the superoxide dismutase and chlorophyll content in durum wheat landraces. Turk J Biol. 2009;33(1):1-7.

135. Mailloux RJ. Mitochondrial antioxidants and the maintenance of cellular hydrogen peroxide levels. Oxid Med Cell Longev. 2018;2018.

136. Liu N, Lin Z, Guan L, Gaughan G, Lin G. Antioxidant enzymes regulate reactive oxygen species during pod elongation in Pisum sativum and Brassica chinensis. PLOS ONE 2014;9(2):e87588.

137. Abid M, Ali S, Qi LK, Zahoor R, Tian Z, Jiang D, et al. Physiological and biochemical changes during drought and recovery periods at tillering and jointing stages in wheat (Triticum aestivum L.). Sci Rep. 2018;8(1):1-15.

138. Qiu Z, Zhu L, He L, Chen D, Zeng D, Chen G, et al. DNA damage and reactive oxygen species cause cell death in the rice local lesions 1 mutant under high light and high temperature. New Phytol. 2019;222(1):349-65.

139. Valifard M, Moradshahi A, Kholdebarin B. Biochemical and physiological responses of two wheat (Triticum aestivum L.) cultivars to drought stress applied at seedling stage. 2012.

140. Devi R, Kaur N, Gupta AK. Potential of antioxidant enzymes in depicting drought tolerance of wheat (Triticum aestivum L.). 2012.

141. Reddy AM, Kumar SG, Jyothsnakumari G, Thimmanaik S, Sudhakar C. Lead induced changes in antioxidant metabolism of horsegram (Macrotyloma uniflorum (Lam.) Verdc.) and bengalgram (Cicer arietinum L.). Chemosphere. 2005;60(1):97-104.

142. Dubey D, Pandey A. Effect of nickel (Ni) on chlorophyll, lipid peroxidation and antioxidant enzymes activities in black gram (Vigna mungo) leaves. Int J Sci Nat. 2011;2(2):395401.

143. Sreekanth T, Nagajyothi P, Lee K, Prasad T. Occurrence, physiological responses and toxicity of nickel in plants. Int J Environ Sci Technol. 2013;10(5):1129-40.

144. Tian X, Lei Y. Nitric oxide treatment alleviates drought stress in wheat seedlings. Biologia plantarum. 2006;50(4):775-8. 
145. Kaur M, Gupta AK, Zhawar VK. Antioxidant response and Lea genes expression under exogenous ABA and water deficit stress in wheat cultivars contrasting in drought tolerance. J Plant Biochem Biotechnol. 2014;23(1):18-30.

146. Nadia K, Naqvi FN. Effect of water stress on lipid peroxidation and antioxidant enzymes in local bread wheat hexaploids. J Food Agric Environ. 2010;8(2):521-6.

147. Feng H, Li X, Duan J, Li H, Liang H. Chilling tolerance of wheat seedlings is related to an enhanced alternative respiratory pathway. Crop Sci. 2008;48(6):2381-8.

148. Hasanuzzaman M, Fujita M. Selenium pretreatment upregulates the antioxidant defense and methylglyoxal detoxification system and confers enhanced tolerance to drought stress in rapeseed seedlings. Biol Trace Elem Res. 2011;143(3):1758-76.

149. Noreen S, Ashraf M, Hussain M, Jamil A. Exogenous application of salicylic acid enhances antioxidative capacity in salt stressed sunflower (Helianthus annuus L.) plants. Pak J Bot. 2009;41(1):473-9.

150. Hussain SS, Kayani MA, Amjad M. Transcription factors as tools to engineer enhanced drought stress tolerance in plants. Biotechnol Prog. 2011;27(2):297-306.

151. He L, Gao Z. Pretreatment of seed with $\mathrm{H}_{2} \mathrm{O}_{2}$ enhances drought tolerance of wheat (Triticum aestivum L.) seedlings. Afr J Biotechnol. 2009;8(22). 


\section{4 mutant} population

Selection on the basis of rust response

$\checkmark$

Collection of yield data of 44 mutant lines

$\underline{\mathrm{M}}_{4}$ generation $\mathrm{n}=\mathbf{4 4}$ mutants

$\underset{\mid}{\stackrel{\text { Selection }}{\longrightarrow}}$

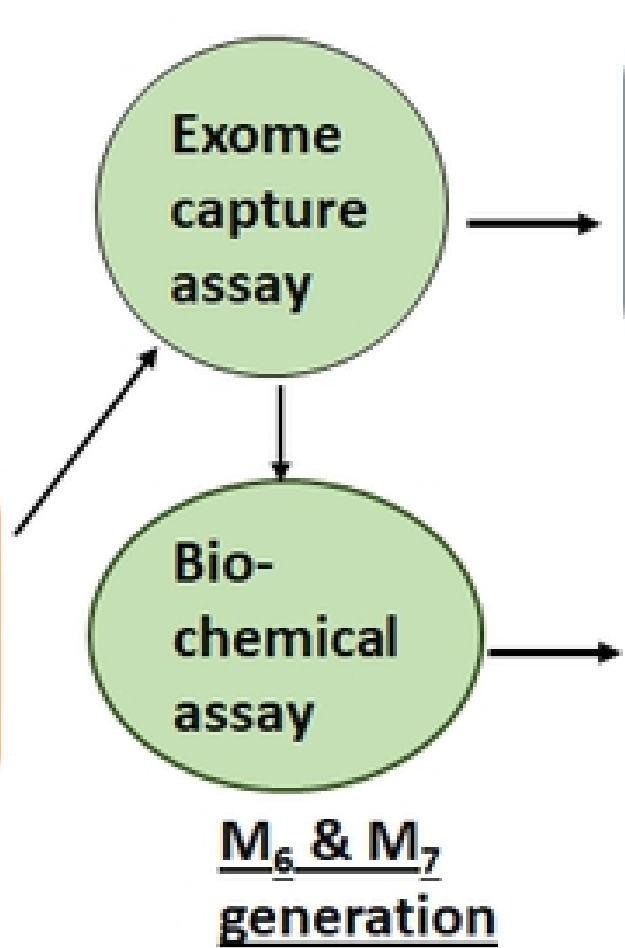

Identification of SCG from all selected genotypes

3D protein structure of identified SCG
$\frac{M_{5} \text { generation }}{n=5 \text { mutants }}$
Selected 5 mutant lines mutant lines

$\mathrm{M}_{5}$ generation $\mathrm{n}=\mathbf{2 4}$ mutants
Screening on the basis of high yield
Screening on the basis of response to drought (physiological parameters)
Association of identified gene in one of the genotype with biochemical assay data in both $M_{6} \& M_{7}$ generations

Flow chart showing the narrow down strategy for the identificati 


\section{Hydrogen per oxidase}

0.80

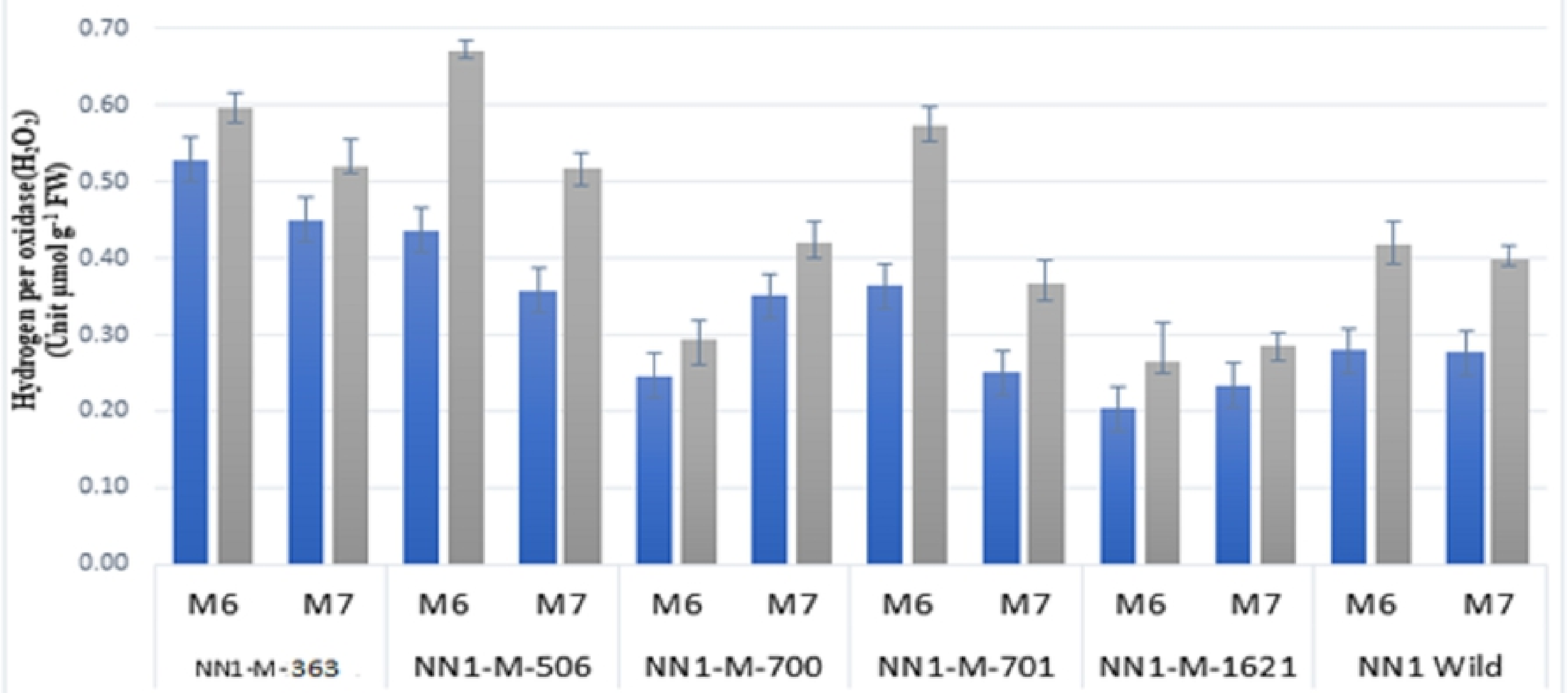

a $W_{1}=W_{2}$

$\mathrm{H} 2 \mathrm{O} 2$ Activity in NN-Gandum-1 genotype under well-watered (cc 


\section{Malondialdehyde contents}

4.50

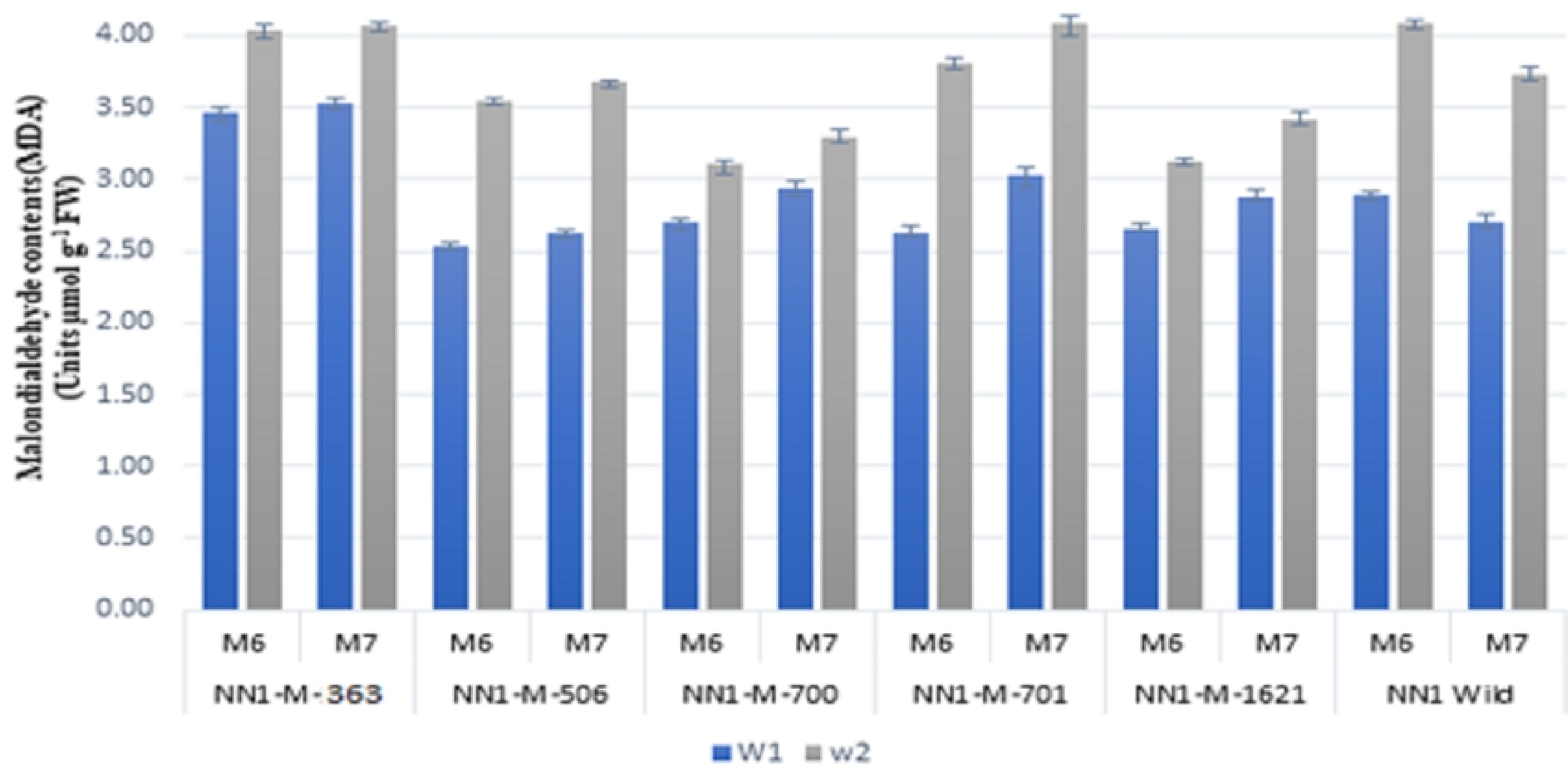

MDA contents in NN-Gandum-1 genotype under well-watered (c 


\section{Catalase Activity}

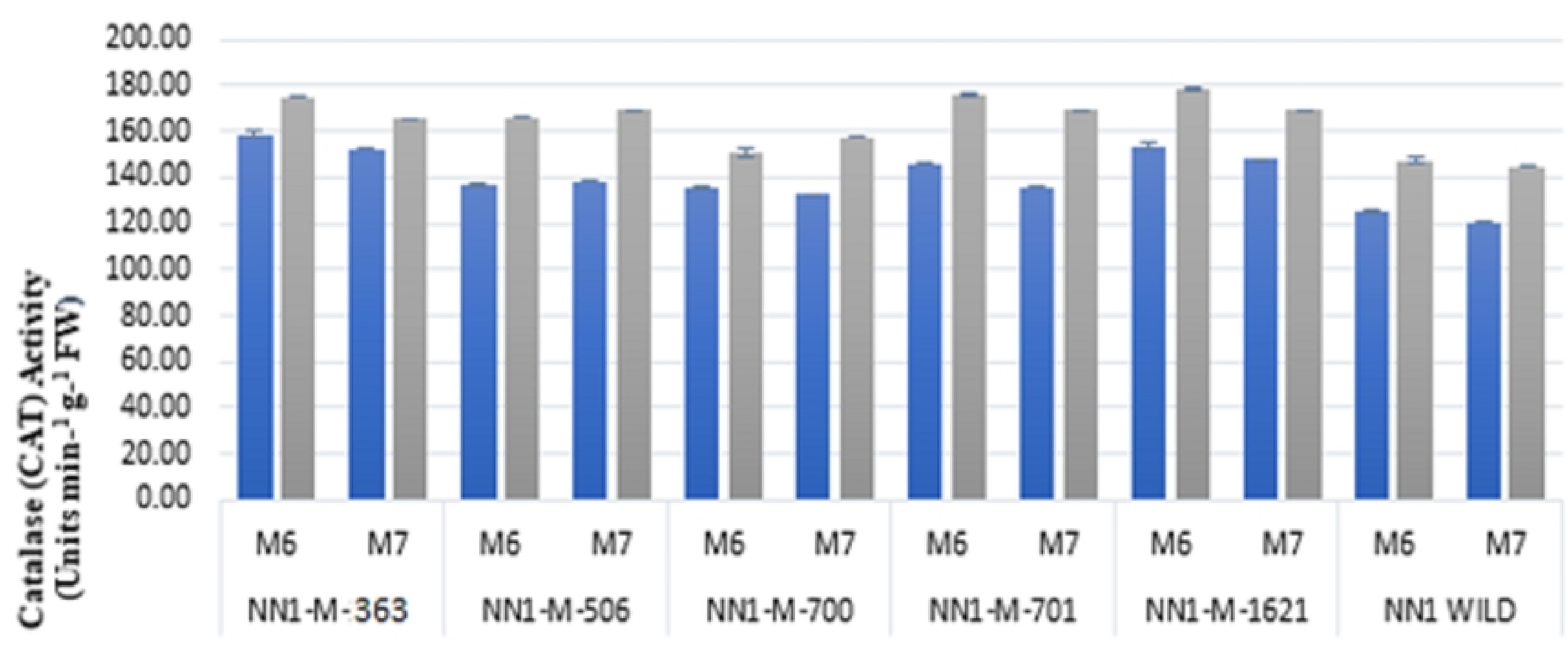

Genotypes of NNl (M6 and M7 Generation)

a $\mathrm{W} 1=\mathrm{W} 2$

CAT activity in NN-Gandum-1 genotype under well-watered (con 


\section{Ascorbate Peroxidase Activity}

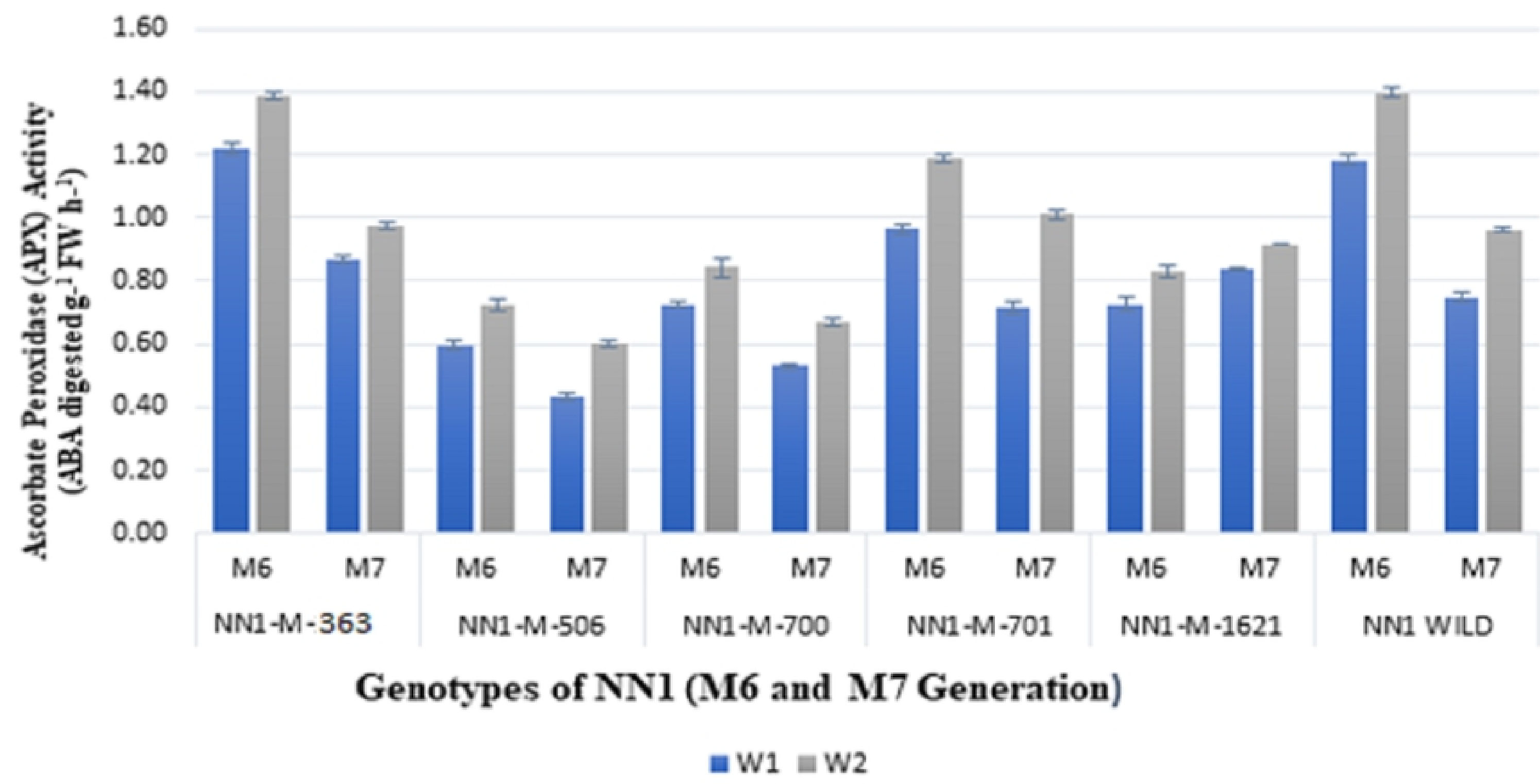

APX activity in NN-Gandum-1 genotype under well-watered (con 


\section{Peroxidase Activity}

2.50

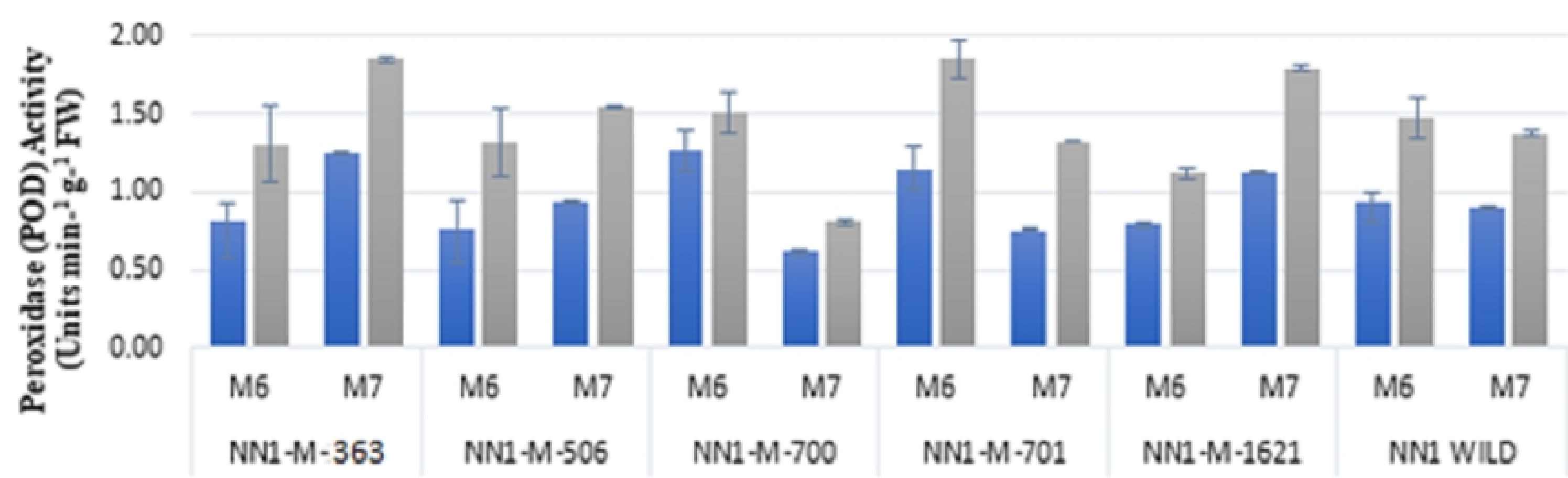

Genotypes of NNl (M6 and M7 Generation) aW1 $=\mathrm{W}_{2}$

POD activity in NN-Gandum-1 genotype under well-watered (cor 


\section{Superoxide Dismutase Activity}

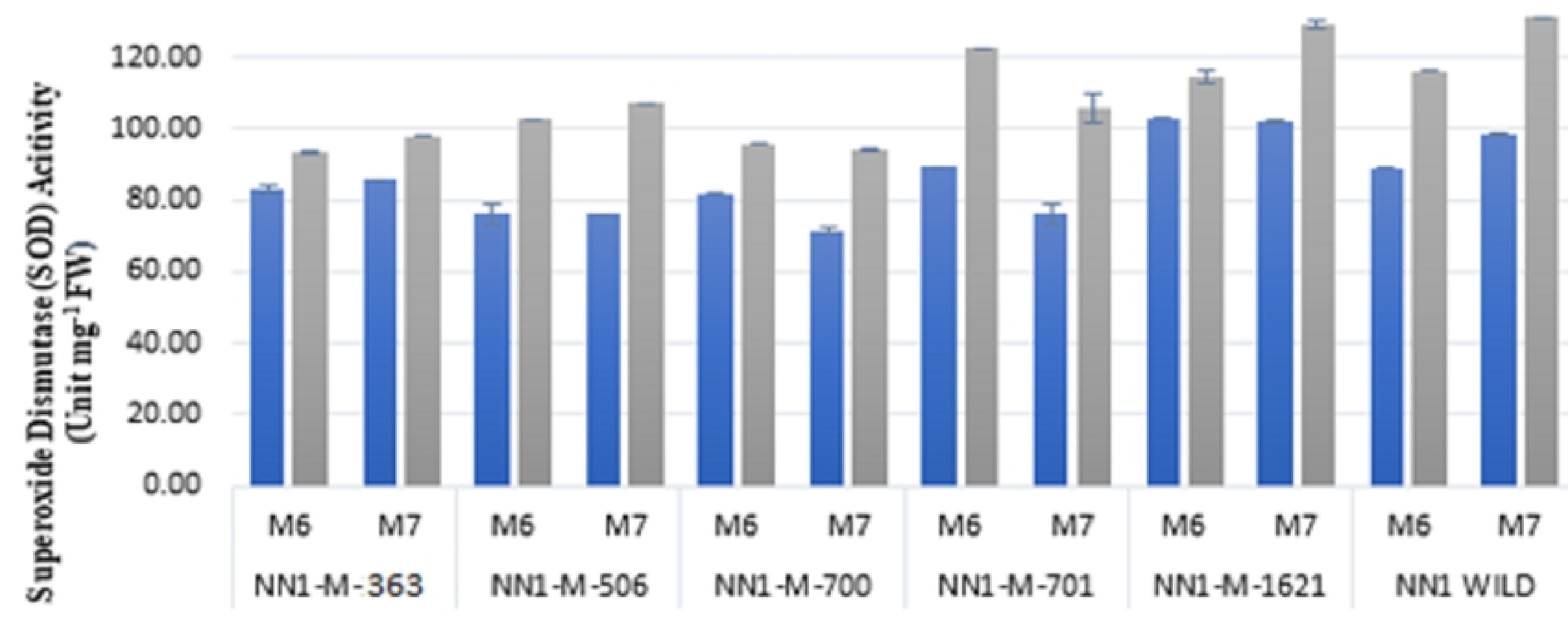

Genotypes of NN1 (M6 and M7 Generation)

$$
\pm W_{1}=W_{2}
$$

SOD activity in NN-Gandum-1 genotype under well-watered (cor 


\section{Total Free Amino Acid}

30.00

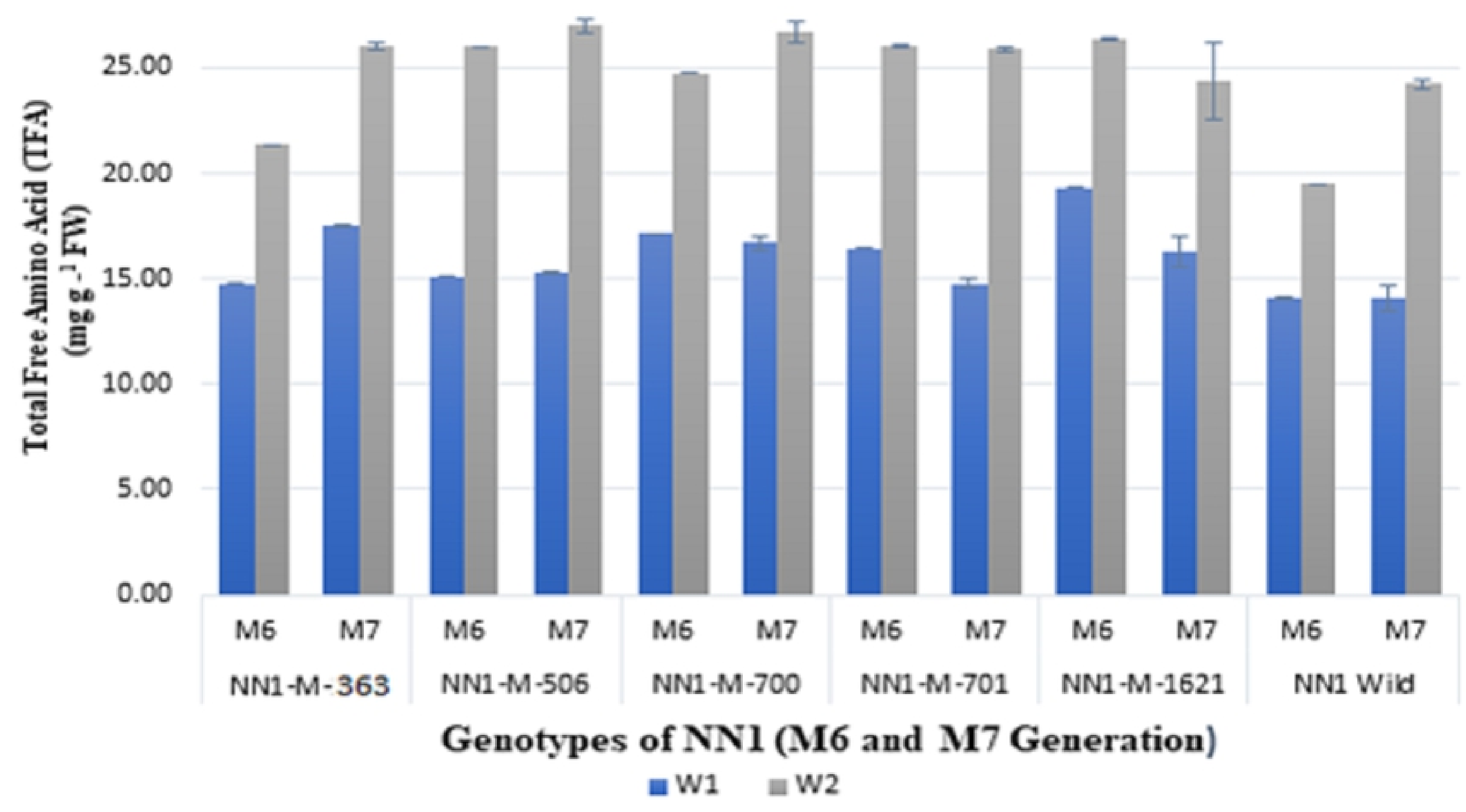

Total Free Amino Acids (TFAs) in NN-Gandum-1 genotype under 


\section{Total Soluble Sugars}

3.00

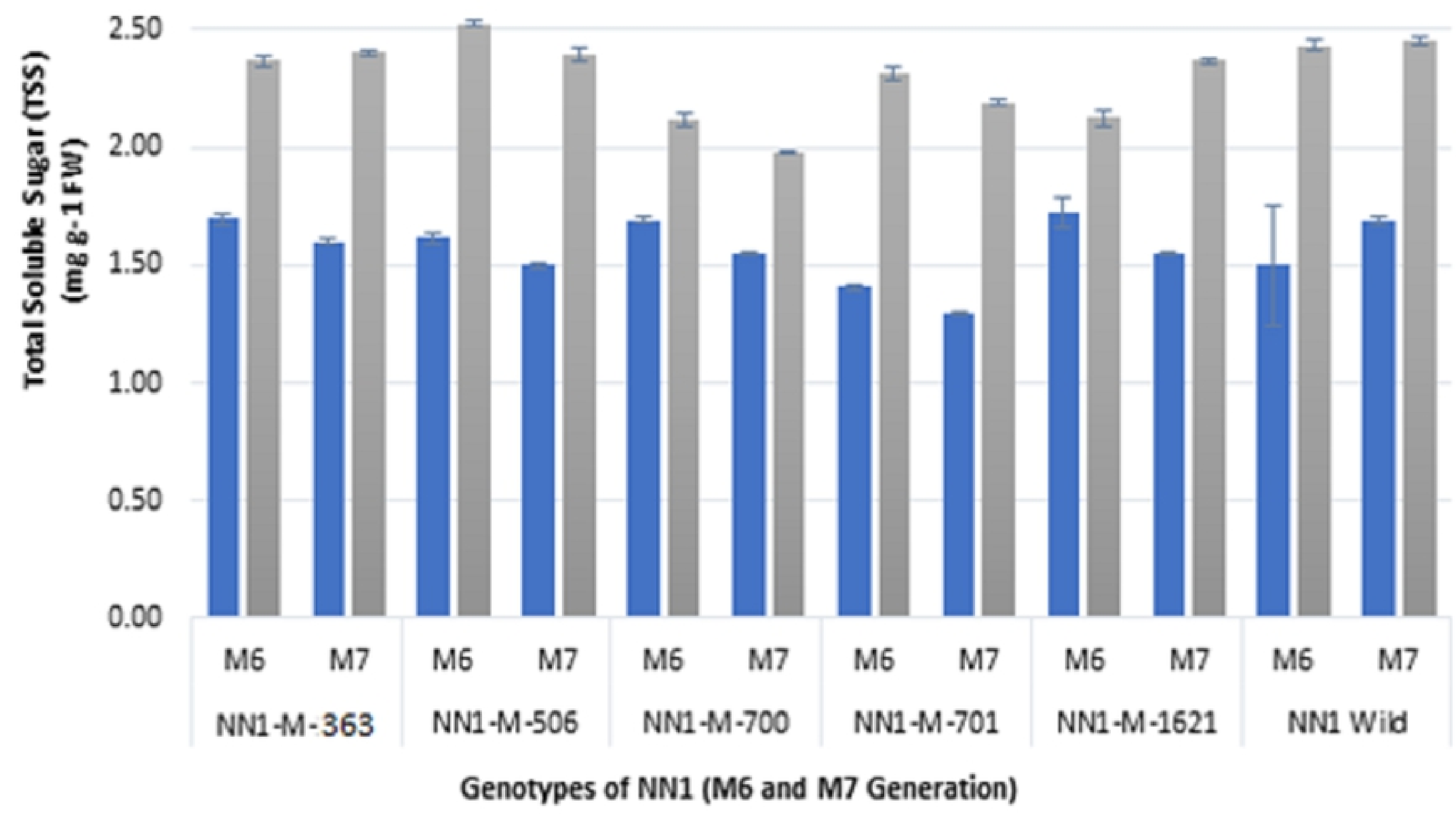

미료 $=W_{2}$

Total Soluble Sugars (TSSs) in NN-Gandum-1 genotype under we 


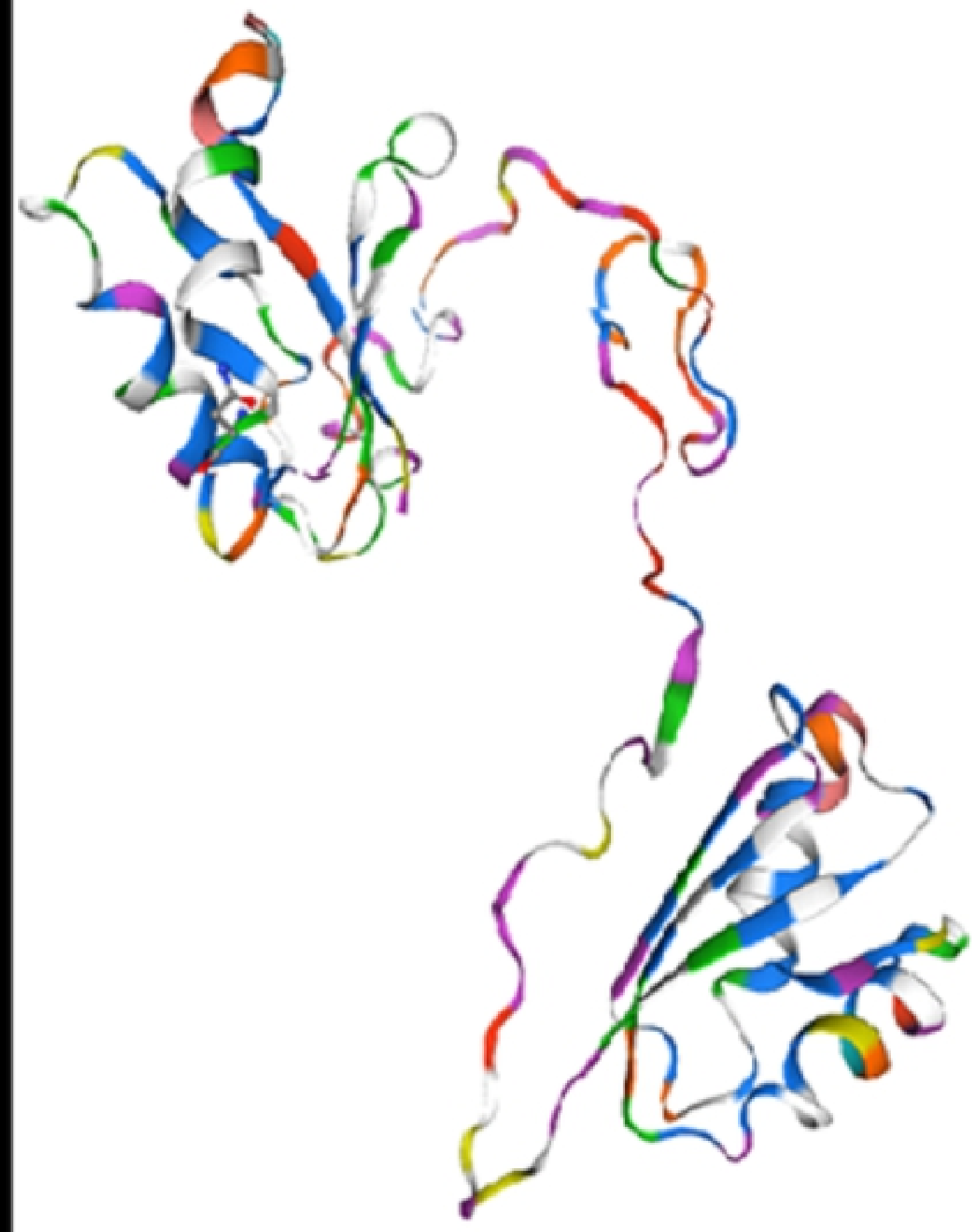

Wildtype protein

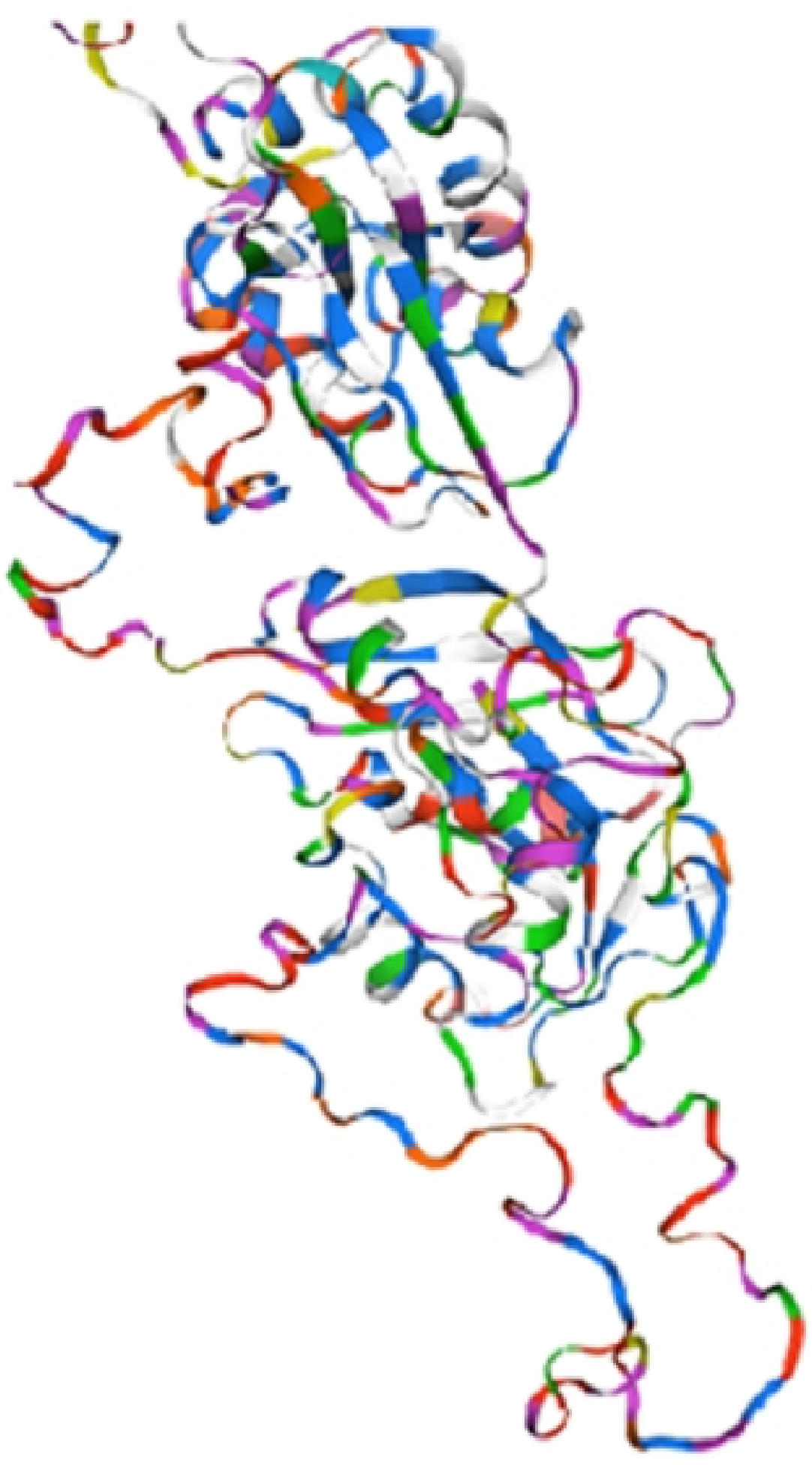

Mutant Protein

3D protein structure of single copy gene HMA identified in genot 


\section{Physiological Parameters}

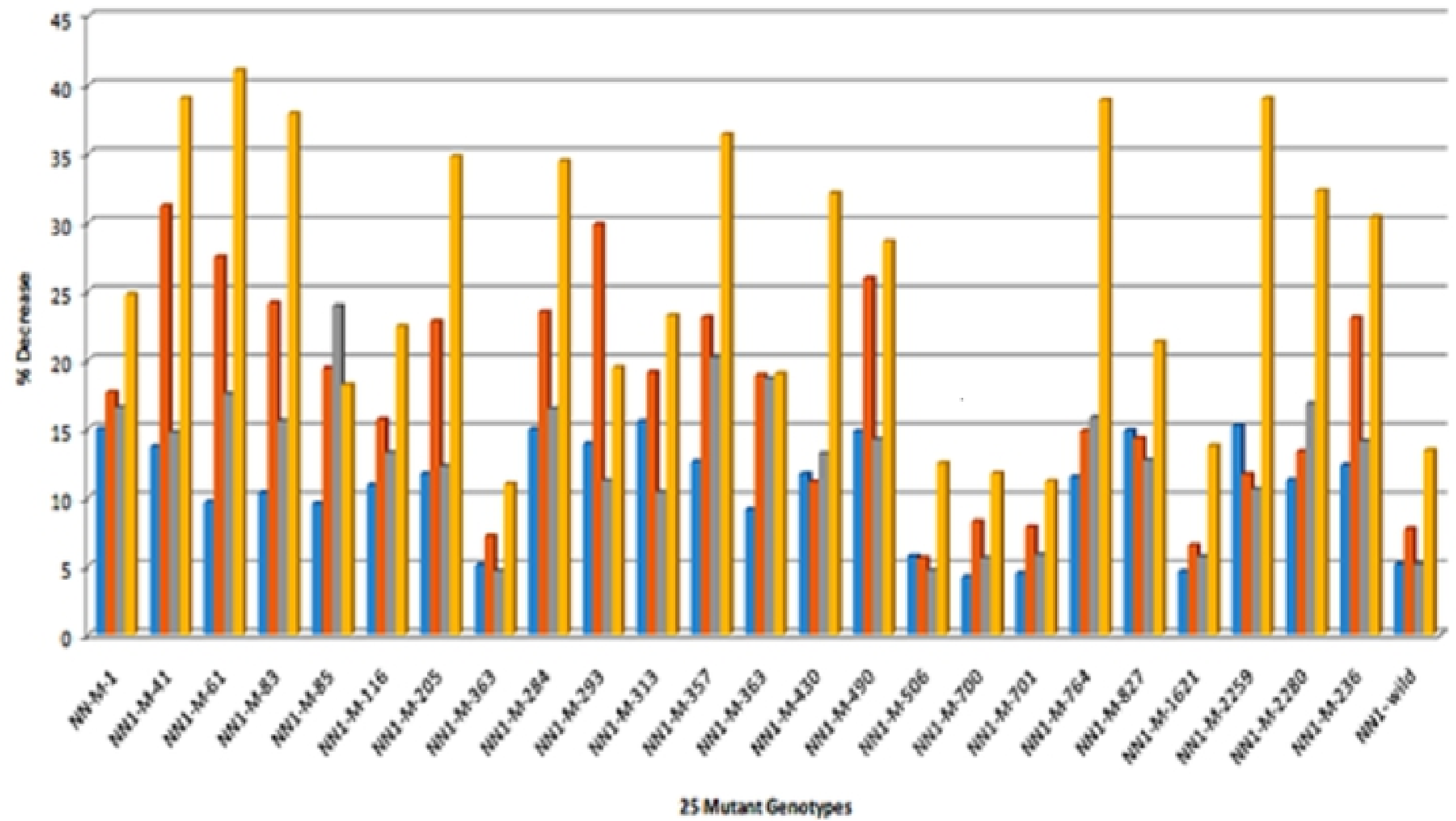

I parre leatsutice

"Sub-Stomues Conductuose

"Iranspirzion Rate

"Photorpthatic Rate 


\section{Total Chlorophyll Contents}

\subsection{0}
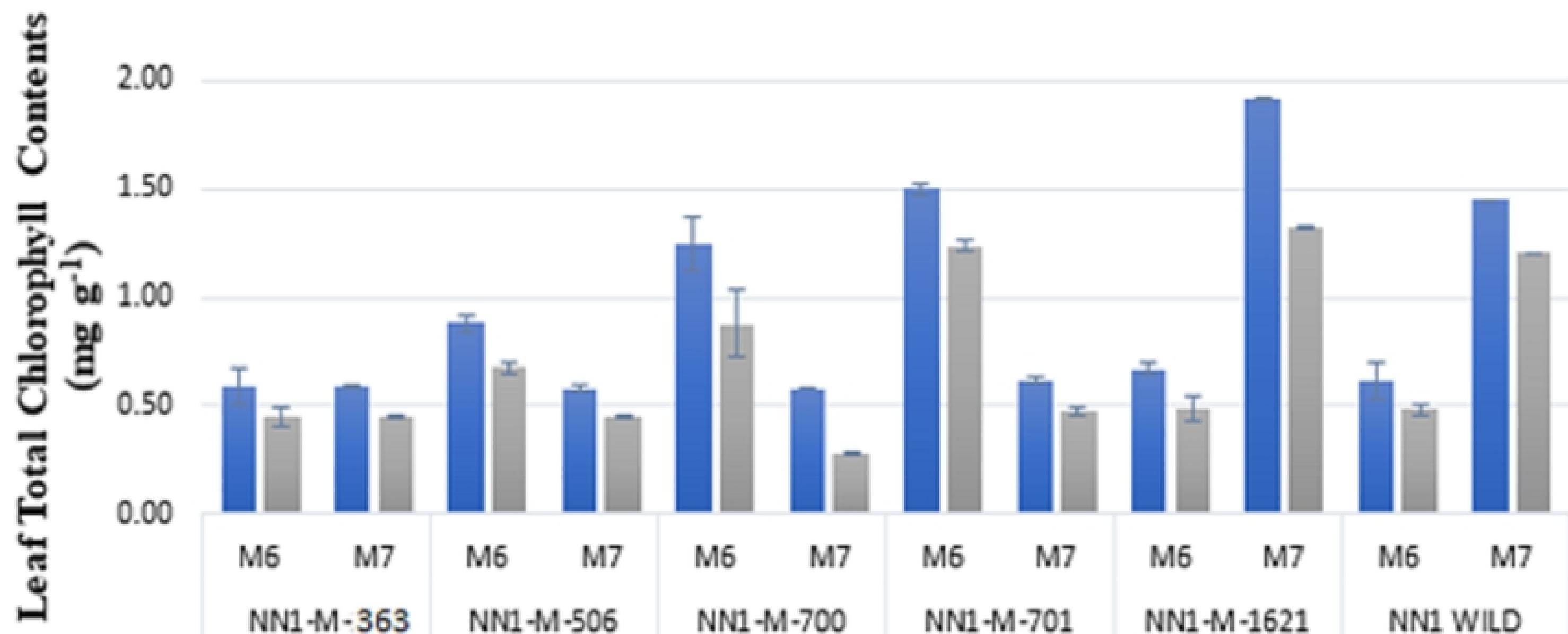

M6

M7

M7

M6

M7

M6

M7

M6

M7

M6

M7

NN1-M-363

NN1-M-506

NN1 $-\mathrm{M}-700$

NN1-M-701

NN1-M-1621

NN1 WILD

Genotypes of NNl (M6 and M7 Generation)

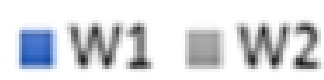

Total Chlorophyll Contents in NN-Gandum-1 genotype under we 


\section{Carotenoids Contents}

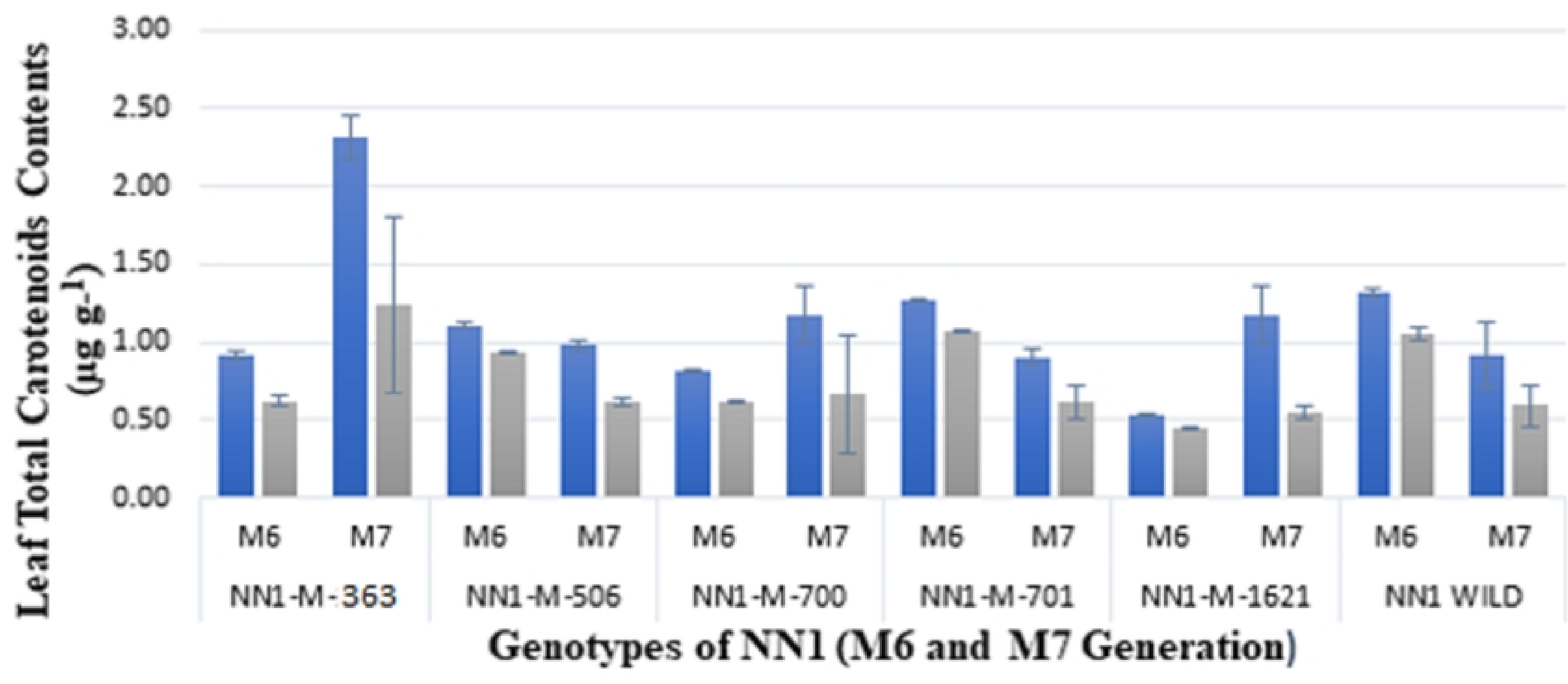

매1 $=\mathrm{W}_{2}$

Carotenoid Contents in NN-Gandum-1 genotype under well-wat 


\section{Leaf Proline Contents}

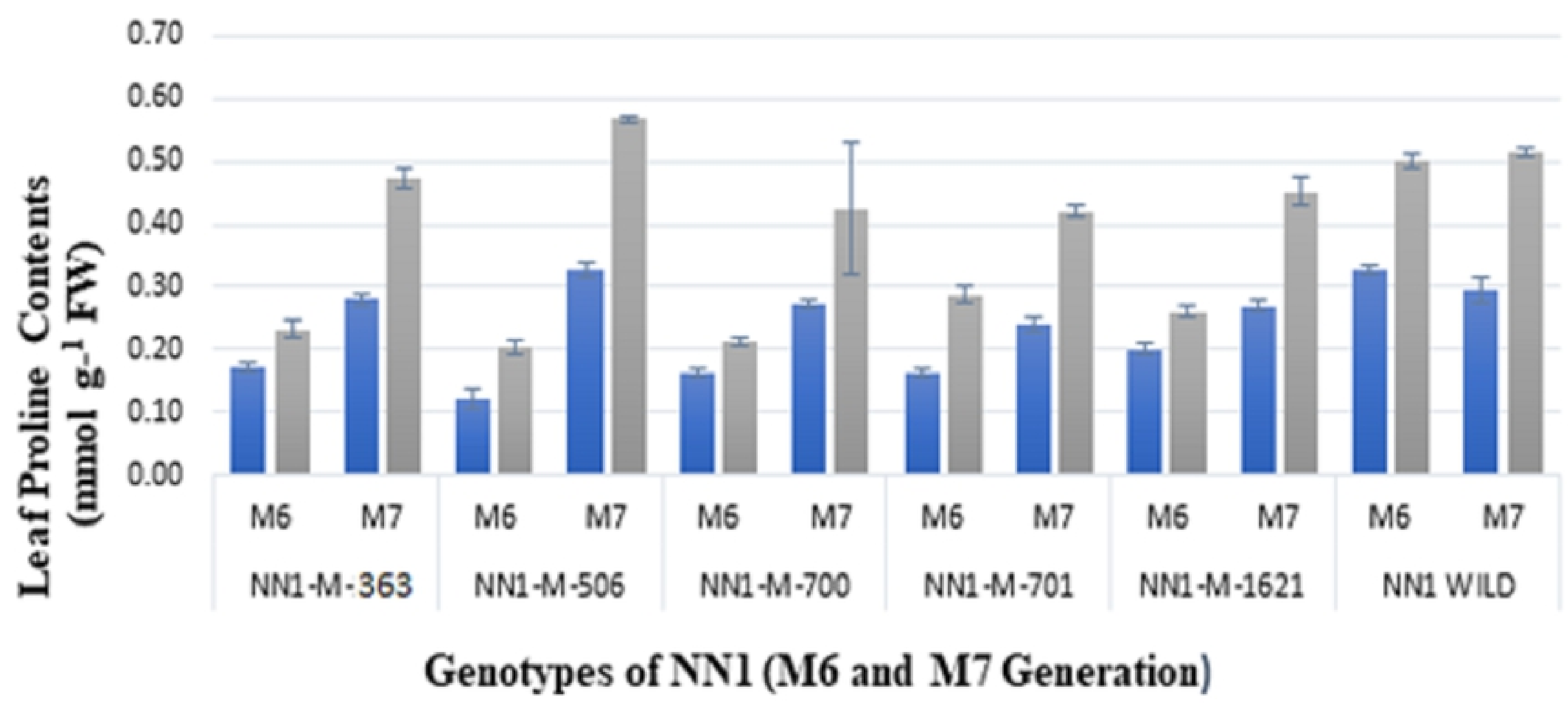

블 $1=W_{2}$

Proline Contents in NN-Gandum-1 genotype under well-waterec 


\section{Total Soluble Proteins}

\subsection{0}

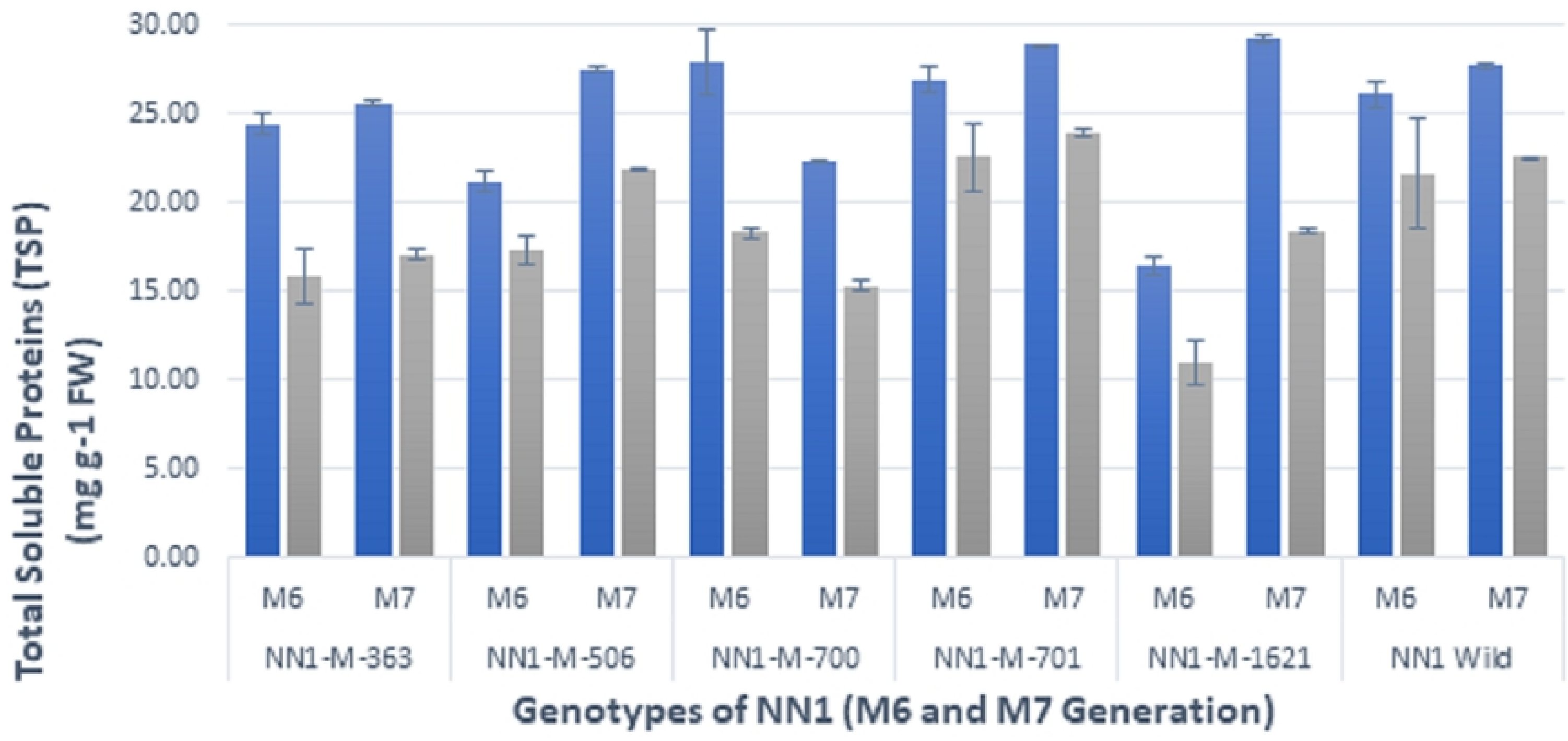

ㅁ1 $=W_{2}$

Total Soluble Proteins (TSPs) in NN-Gandum-1 genotypes 